Review

\title{
Recent Advances on Electro-Oxidation of Ethanol on Pt- and Pd-Based Catalysts: From Reaction Mechanisms to Catalytic Materials
}

\author{
Ye Wang ${ }^{1}$, Shouzhong Zou ${ }^{2, *}$ and Wen-Bin Cai ${ }^{1, *}$
}

1 Shanghai Key Laboratory for Molecular Catalysis and Innovative Materials, Collaborative Innovation Center of Chemistry for Energy Materials and Department of Chemistry, Fudan University, Shanghai 200433, China, E-Mail: 11110220009@fudan.edu.cn

2 Department of Chemistry, American University, Washington, DC 20016, USA

* Authors to whom correspondence should be addressed; E-Mails: szou@american.edu (S.Z.); wbcai@fudan.edu.cn (W.-B.C.); Tel.: +1-202-885-1763 (S.Z.); +86-21-5566-4050 (W.-B.C.); Fax: +1-202-885-1752 (S.Z.); +86-21-6564-1740 (W.-B.C.).

Academic Editor: Minhua Shao

Received: 8 June 2015 / Accepted: 13 August 2015 / Published: 2 September 2015

\begin{abstract}
The ethanol oxidation reaction (EOR) has drawn increasing interest in electrocatalysis and fuel cells by considering that ethanol as a biomass fuel has advantages of low toxicity, renewability, and a high theoretical energy density compared to methanol. Since EOR is a complex multiple-electron process involving various intermediates and products, the mechanistic investigation as well as the rational design of electrocatalysts are challenging yet essential for the desired complete oxidation to $\mathrm{CO}_{2}$. This mini review is aimed at presenting an overview of the advances in the study of reaction mechanisms and electrocatalytic materials for EOR over the past two decades with a focus on Pt- and Pd-based catalysts. We start with discussion on the mechanistic understanding of EOR on $\mathrm{Pt}$ and Pd surfaces using selected publications as examples. Consensuses from the mechanistic studies are that sufficient active surface sites to facilitate the cleavage of the $\mathrm{C}-\mathrm{C}$ bond and the adsorption of water or its residue are critical for obtaining a higher electro-oxidation activity. We then show how this understanding has been applied to achieve improved performance on various Pt- and Pd-based catalysts through optimizing electronic and bifunctional effects, as well as by tuning their surface composition and structure. Finally we point out the remaining key problems in the development of anode electrocatalysts for EOR.
\end{abstract}


Keywords: ethanol; electrocatalysts; electro-oxidation; mechanism; rational design

\section{Introduction}

Rising demands for energy coupled with concerns over ecosystem damage and growing consumption of non-regenerative fossil energy pose a great need for clean and efficient power sources [1-4]. Fuel cells are widely considered as sustainable energy conversion devices. Low-temperature fuel cells are undergoing rapid development for mobile applications and in particular for the transport sector. Among different fuels that have been used for fuel cells, hydrogen, methanol, and ethanol have been the most explored and each has its advantages and disadvantages. The choice of the fuel depends on the applications. Proton exchange membrane fuel cells (PEMFCs) using hydrogen as the fuel have the advantages of low operating temperature, sustained operation at high current densities, low weight, compactness, and suitability for discontinuous operation, but face challenges in the production, storage and transport of hydrogen. As an alternative fuel, ethanol which can be produced on a massive scale from biomass feed stocks originating from agriculture (first-generation bioethanol), forestry, and urban residues (second-generation bioethanol), is attracting increasing interest [5-8]. Compared to another common fuel, methanol, ethanol complements the shortcomings of methanol owing to its non-toxicity, higher boiling point, and most importantly, renewability. In addition, ethanol has a high specific energy of $8.01 \mathrm{kWh} \cdot \mathrm{kg}^{-1}$, which is comparable to that of gasoline [9,10]. Nevertheless, the relatively sluggish kinetics for the ethanol oxidation reaction (EOR) presents a major roadblock for the development of direct ethanol fuel cells (DEFCs) [3,7]. Higher performance catalysts are needed to overcome this bottleneck. A detailed understanding of the reaction mechanism and in particular of the rate-limiting step(s) in EOR under continuous reaction conditions is of critical importance for the design of highly active catalysts [11,12]. Although numerous experimental studies using Fourier transform infrared spectroscopy (FTIR) [13-26] or differential electrochemical mass spectrometry (DEMS) [27-37], as well as theoretical studies [38-45] have been conducted to understand the EOR process, a detailed mechanism of EOR remains unclear or even contradictory. Nevertheless, a so-called dual-pathway (C1 and C2) mechanism has been largely agreed upon: the C1 pathway proceeds via adsorbed carbon monoxide $\left(\mathrm{CO}_{\mathrm{ads}}\right.$ ) intermediate to form $\mathrm{CO}_{2}$ (or carbonate in alkaline solutions) by delivering 12 electrons, and the $\mathrm{C} 2$ pathway mainly leads to the formation of acetic acid (or acetate in alkaline solutions) by delivering four electrons and/or acetaldehyde by delivering two electrons. Though a higher electro-efficiency can be achieved by the C1 pathway, the C2 pathway is generally dominant in the overall EOR [46-49]. Therefore selectively enhancing the $\mathrm{C} 1$ pathway by rational design of high performance catalysts is an effective way to increase the DEFC efficiency.

Pt is the most commonly used catalytic metal in the anode of DEFCs because of its excellent properties in the adsorption and dissociation of ethanol. However, the cost of Pt is a major impediment in the commercialization of fuel cell technology, because it alone accounts for approximately 54\% of the total fuel cell stack cost [3]. On the other hand, Pd has similar catalytic properties to Pt (in the same group of the periodic table, having the same face centered cubic (fcc) crystal structure and a similar 
atomic size) [12], but is much lower in material cost. Moreover, the abundance of Pd on the Earth's crust is 200 times higher than that of Pt (0.6 part per billion (ppb) vs. 0.003 ppb), making it very attractive for long-term industrial applications [3]. Though Pt and Pd show relatively good activity, a complete oxidation of ethanol in both acidic and/or basic media remains virtually impossible. A large number of studies have reported the enhancement of the electrocatalytic performance of Pt-M and Pd-M binary or ternary catalysts by adding additional elements such as metallic elements $\mathrm{Ru}, \mathrm{Sn}, \mathrm{Ir}, \mathrm{Bi}$, $\mathrm{Rh}, \mathrm{Mo}, \mathrm{Fe}, \mathrm{Co}, \mathrm{Cu}, \mathrm{Ni}, \mathrm{Au}, \mathrm{Ag}$ and nonmetallic elements, oxides etc. Yet, there are many unanswered questions regarding the role of these foreign materials in improving the electrocatalytic activities. To rationally design Pt- or Pd-based materials as anode catalysts and to develop DEFC technology, a better understanding of the structure-electrocatalytic activity relationships in the EOR is a pre-requisite.

In this review, by discussing selected publications on mechanism studies and the development of advanced catalysts, we present an overview of how the achievements in mechanism studies have been used to guide the rational design of catalysts. Recent advancements in fundamental studies as well as in developing promising new anode EOR catalysts are briefly surveyed. Finally, we summarize the key problems in the investigation on catalysts for EOR and provide outlooks for their future development. Because EOR is under active research, it is impossible to cover every aspect of the new developments. We therefore focus our discussion on Pt- and Pd-based catalysts. Selected examples are only used to facilitate the discussion and inevitably we may have omitted other significant contributions in the field.

\section{Reaction Mechanism of EOR}

Activity, selectivity, and stability are critical issues that need to be addressed for any catalysts. Comprehensive fundamental studies of EOR form the basis of design rules for high efficiency catalysts $[2,21,26,47,50]$. A great deal of work on the mechanisms of Pt- or Pd-based catalysts have been devoted to solve the long-standing puzzle concerning the intermediates and the products from EOR. The pioneering work on the mechanism of EOR can be traced back to the 1950s [51] and now has been evolved into a commonly accepted dual-pathway mechanism on Pt- or Pd-based catalysts in either acidic or alkaline media as shown in Figure 1. [44,47,52-55].

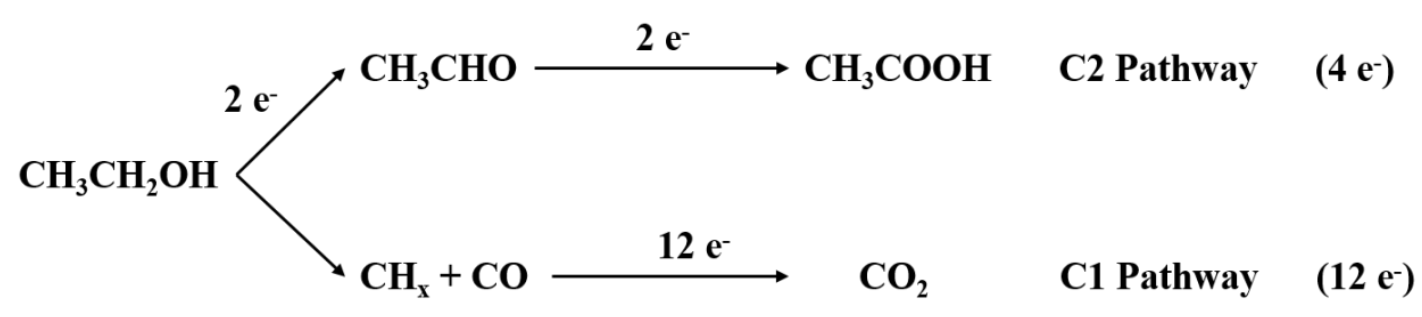

Figure 1. Schematic representation of the parallel pathways for ethanol oxidation on $\mathrm{Pt}$ electrodes in acidic media.

The $\mathrm{C} 1$ pathway is the complete oxidation of ethanol to $\mathrm{CO}_{2}$ or carbonates via $\mathrm{CO}_{\text {ads }}$ intermediate by delivering 12 electrons and the $\mathrm{C} 2$ pathway is the partial oxidation of ethanol to acetate by delivering four electrons or to acetaldehyde by delivering two electrons without the breaking of the $\mathrm{C}-\mathrm{C}$ bond as shown in the following equations: 


\section{C1 pathway:}

$$
\begin{gathered}
\mathrm{CH}_{3}-\mathrm{CH}_{2} \mathrm{OH}+3 \mathrm{H}_{2} \mathrm{O} \rightarrow 2 \mathrm{CO}_{2}+12 \mathrm{H}^{+}+12 \mathrm{e}^{-} \\
\mathrm{CH}_{3}-\mathrm{CH}_{2} \mathrm{OH}+5 \mathrm{H}_{2} \mathrm{O} \rightarrow 2 \mathrm{HCO}_{3}{ }^{-}+14 \mathrm{H}^{+}+12 \mathrm{e}^{-} \\
\mathrm{CH}_{3}-\mathrm{CH}_{2} \mathrm{OH}+5 \mathrm{H}_{2} \mathrm{O} \rightarrow 2 \mathrm{CO}_{3}{ }^{2-}+16 \mathrm{H}^{+}+12 \mathrm{e}^{-}
\end{gathered}
$$

\section{C2 pathway:}

$$
\begin{gathered}
\mathrm{CH}_{3}-\mathrm{CH}_{2} \mathrm{OH}+\mathrm{H}_{2} \mathrm{O} \rightarrow \mathrm{CH}_{3}-\mathrm{COOH}+4 \mathrm{H}^{+}+4 \mathrm{e}^{-} \\
\mathrm{CH}_{3}-\mathrm{CH}_{2} \mathrm{OH} \rightarrow \mathrm{CH}_{3}-\mathrm{CHO}+2 \mathrm{H}^{+}+2 \mathrm{e}^{-}
\end{gathered}
$$

Adsorbed CO, C1 and C2 hydrocarbon residues have been identified as the major adsorbed intermediates on Pt- or Pd-based catalysts, while acetaldehyde and acetic acid have been detected as the main by-products using techniques such as infrared spectroscopy [13-26], online DEMS [27-37], ion chromatography [56,57], and liquid chromatography [14]. However, EOR has been shown to occur via a series of complex reactions involving a number of sequential and parallel reaction steps, thus resulting in more than 40 possible volatile and adsorbed intermediates or oxidative derivatives [43]. Previous studies agree that CO is a dominant adsorbed species formed during EOR, however, they disagree on details such as the adsorbed state of other intermediates and on the question of the rate limiting steps: the adsorption of intermediate or the cleavage of $\mathrm{C}-\mathrm{C}$ bond or the formation of $\mathrm{OH}$ or oxides [20,23,26,31,38,45,47,54]. In the following we summarize EOR mechanisms developed in the last two decades from experimental as well as DFT calculation studies and discuss the unsolved issues in understanding the EOR mechanism.

\subsection{Experimental Detection and Quantification of Reaction Intermediates and Products}

As mentioned above, the reaction mechanism is complex involving several adsorbed intermediates and numerous products and by-products. Determining product distribution and identifying reactive intermediates are the keys for solving the EOR mechanism puzzle and therefore are always hot topics under active debate. To address these two issues, many efforts have been made to combine traditional electrochemical methods (cyclic voltammetry, chronoamperometry, rotating disc electrodes, etc.) with other physicochemical methods, such as in situ FTIR [9,13-24], broadband sum-frequency generation (BB-SFG) spectroscopy [58], DEMS [16,27-36], HPLC [56,57], GC [14], electrochemical quartz crystal microbalance (EQCM) [59] and in situ NMR [60] to probe the adsorbed intermediates and/or quantify the reaction products and by-products [56]. We devote the following section to summarize and discuss how these techniques were used for product quantification as well as the clarification of intermediates, starting with FTIR studies and followed by mass spectrometric results.

In the early days Weaver and co-workers [25,61,62] adopted real-time FTIR spectroscopy to study EOR on Pt surfaces in acidic media, and found that the final reaction products included acetic acid, acetaldehyde along with a smaller amount of $\mathrm{CO}_{2}$. Their work was the first quantification of specific oxidation products, and provides values of the effective absorption coefficient, Eeff of $\mathrm{CO}_{2}$, acetic acid, and acetaldehyde which are $3.5 \times 10^{4}, 5.8 \times 10^{3}$, and $2.2 \times 10^{3} \mathrm{M}^{-1} \cdot \mathrm{cm}^{-2}$, respectively. The yields of oxidation products were calculated using respective integrated band intensities $\left(A_{i}\right)$, and the amount of 
a given species $Q\left(\mathrm{~mol} \cdot \mathrm{cm}^{-2}\right)$ trapped inside the thin layer between the electrode surface and the optical window followed the relationship:

$$
Q=\frac{A_{\mathrm{i}}}{\varepsilon_{\text {eff }}}
$$

To better compare the selectivity and activity of EOR on catalysts, Adzic's [9] group applied in situ infrared reflection-absorption spectroscopy (in situ IRRAS) to quantify the ratio of C1 pathway to C2 pathway on the ternary $\mathrm{Pd}-\mathrm{Rh}-\mathrm{SnO}_{2} / \mathrm{C}$ electrocatalysts using the following Equation (7):

$$
\frac{C_{\mathrm{CO}_{2}}}{C_{\mathrm{CH}_{3} \mathrm{COOH}}+C_{\mathrm{CH}_{3} \mathrm{CHO}}}=\frac{6 \times Q_{\mathrm{CO}_{2}}}{4 \times Q_{\mathrm{CH}_{3} \mathrm{COOH}}+2 \times Q_{\mathrm{CH}_{3} \mathrm{CHO}}}
$$

where $\mathrm{C}_{\mathrm{CO}_{2}}$ and $\mathrm{C}_{\mathrm{CH}_{3} \mathrm{COOH}}+\mathrm{C}_{\mathrm{CH}_{3} \mathrm{CHO}}$ represent the charges associated with the total oxidation pathway (C1) and the partial oxidation pathway (C2), respectively.

As can be seen from reactions 1-5, water, or its adsorption residue (adsorbed $\mathrm{OH}$ ) is involved in EOR and therefore the product distribution strongly depends on the nature of the electrolyte, such as the concentration of ethanol, $\mathrm{pH}$, or the anion [18,63,64]. Camara and Iwasita [55] systematically investigated the effects of ethanol concentration on the product distribution on polycrystalline Pt by FTIR. They found that the C1 pathway is more pronounced at low ethanol concentration (below $0.1 \mathrm{M}$ ) with negligible acetaldehyde. When the ethanol concentration was higher than $0.2 \mathrm{M}$, the formation of $\mathrm{CO}_{2}$ and acetic acid was inhibited and acetaldehyde was the main product.

Recently the fast development of anion exchange membranes has renewed the interest in the development of alkaline polymer electrolyte fuel cells. In alkaline media, a facile EOR can be achieved less costly with relatively abundant non-Pt metal catalysts. However, it is not clear whether or to what extent the mechanism proposed for EOR on Pt in acidic media can be extended to basic media. By combining electrochemical and spectroscopic techniques (SERS and in situ FTIR), Koper's group $[18,54,65]$ showed that the activity of the reaction on Pt electrodes increases significantly when the $\mathrm{pH}$ of the electrolyte was higher than 10. Detailed mechanisms were proposed for EOR at low electrolyte $\mathrm{pH}(<6)$ and at high electrolyte $\mathrm{pH}(>11)$ as shown in Figure 2:

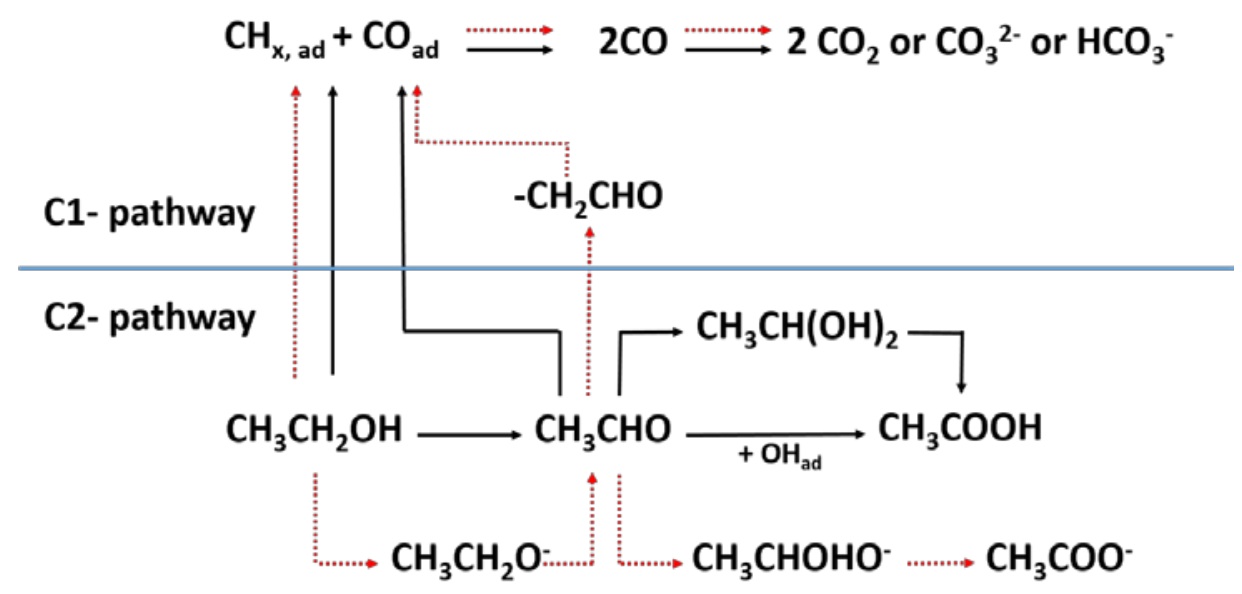

Figure 2. Proposed reaction mechanism for electro-oxidation of ethanol on Pt electrodes. Solid arrows denote the mechanism at low electrolyte $\mathrm{pH}$, while dashed arrows denote the mechanism at high electrolyte $\mathrm{pH}$. Adapted from Reference [18]. 
On the other hand, based on their in situ FTIR spectroscopic results in studying EOR on Pt in alkaline media, Christensen and his co-workers [20] proposed that in contrast to the acidic solutions, under alkaline conditions, the intermediates interact with the surface through $\mathrm{O}$ rather than $\mathrm{C}$ as shown in Figure 3. $\mathrm{Pt}_{\mathrm{s}}-\mathrm{CH}_{2}-\mathrm{C}(=\mathrm{O})-\mathrm{O}-\mathrm{Pt}_{\mathrm{s}}$ was speculated as a new intermediate, and the solution acetate species was the predominant product.

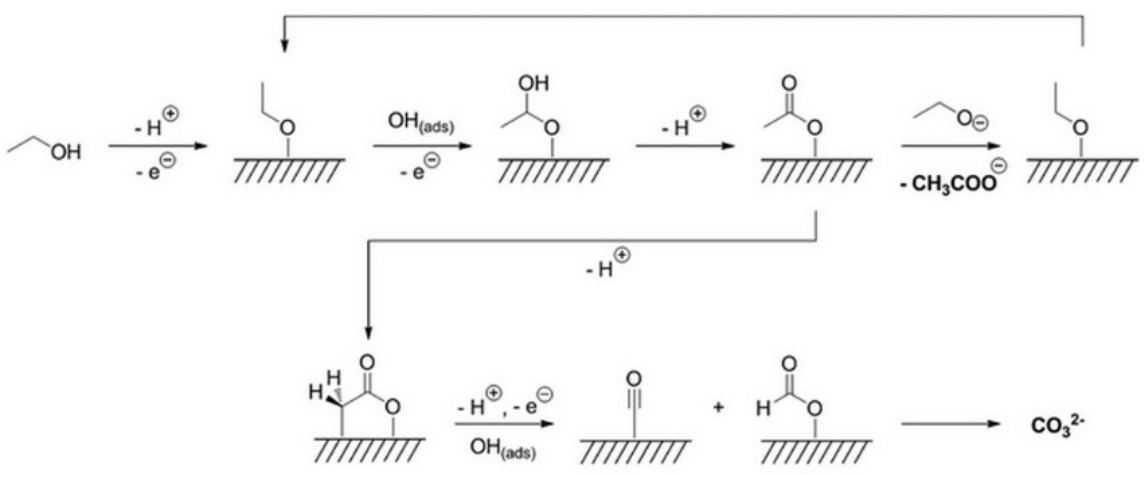

Figure 3. The mechanism of ethanol oxidation at polycrystalline Pt in alkaline solutions proposed by Christensen. Reproduced with permission from Reference [20] Copyright 2012, American Chemical Society.

Pd exhibits a much higher electrocatalytic activity in alkaline media compared to Pt due to its higher oxophilicity and relatively inert nature $[17,47,66]$. Ethanol oxidation on Pd is dramatically affected by the $\mathrm{pH}$ of the solution: virtually no reaction occurs in acidic solutions, while the reaction is fast in alkaline solutions. Through IRRAS studies [19], it was demonstrated that the oxidation of ethanol is incomplete on Pd electrodes and the main product is acetate. In addition, a quantitative FTIR study showed the selectivity for ethanol oxidation to $\mathrm{CO}_{2}$ is less than $2.5 \%$ on $\mathrm{Pd}$ in the potential region of -0.60 to $0 \mathrm{~V}$ [67], but it is still slightly higher than that of Pt in alkaline media.

Though the external infrared reflection absorption spectroscopy with a thin-layer configuration enables the evaluation of the selectivity of the reaction products (i.e., $\mathrm{CO}_{2}$, acetate, and acetaldehyde) as a function of the applied potential, it is not sufficiently sensitive to probe low-coverage or weakly adsorbed intermediates and therefore may not provide complete information for understanding the reaction mechanism [68]. In addition the limited mass transport to and from the thin layer can skew or even alter the product distribution [20]. In contrast, attenuated total reflection surface enhanced infrared absorption spectroscopy (ATR-SEIRAS) provides high surface sensitivity and unobstructed mass transport and thus is promising for the complete disclosure of the EOR mechanism [26,69]. Yang et al. [23] recently investigated the surface reaction of ethanol on Pd in alkaline media using ATR-SEIRAS and H-D isotope replacement on $\alpha-C$ to shed new light on the self-dissociation and oxidation processes. As illustrated in Figure 4, ethanol may undergo dehydrogenation at $\alpha$ - $C$ to form adsorbed acetyl rather than acetaldehyde, followed by successive decomposition to form $\mathrm{C} 1$ species, including $\mathrm{CO}_{\mathrm{ad}}$ and $\mathrm{CH}_{x}$ at open circuit potential or lower potentials. Moreover, ATR-FTIR was also adopted to clarify the rate limiting steps on Pd thin film electrodes. It was found that at higher potential the subsequent dissociation ( $\mathrm{C}-\mathrm{C}$ bond breaking) of the adsorbed acetyl species is the rate limiting step rather than the formation of adsorbed acetyl [70]. Thus, despite controversy over the details, the 
reaction pathways for EOR with Pd electrodes in alkaline media are more or less similar to that with Pt electrodes in basic and acidic media.

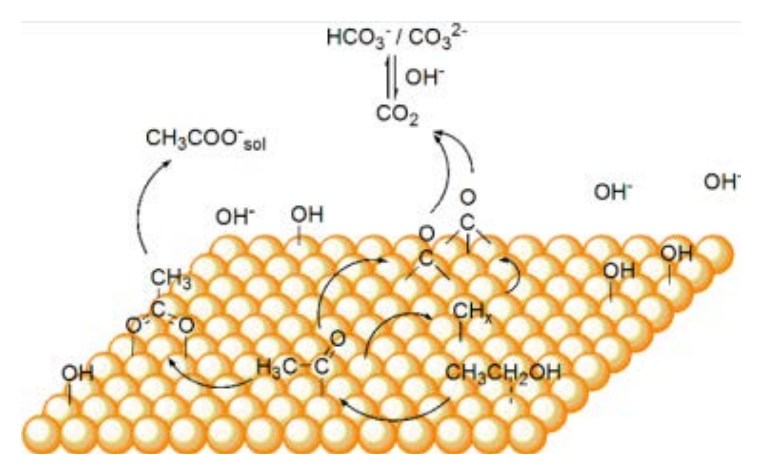

Figure 4. Reaction pathways for interfacial $\mathrm{CH}_{3} \mathrm{CH}_{2} \mathrm{OH}$ at $\mathrm{Pd}$ electrodes in alkaline media. Reproduced with permission from Reference [23]. Copyright 2014, American Chemical Society.

Despite the fact that external IRRAS has been frequently used in identifying reaction intermediates and products, the thin-layer configuration limits its capability for quantification. First, the thin layer structure is not reproducible from experiment to experiment. Second, product accumulation and diffusion out of the thin layer take place at the same time with species-dependent rates, i.e., the diffusion rate varies with different species in the thin layer. $\mathrm{CO}_{2}$ is the most volatile among the three major products and diffuses out faster than $\mathrm{CH}_{3} \mathrm{COOH}$ and $\mathrm{CH}_{3} \mathrm{CHO}$, resulting in its lower estimation. Complimentary to IR spectroscopy, on-line DEMS can provide accurate quantitative information on ethanol oxidation products. In fact, mass spectrometry has often been used to study EOR in conjunction with IR spectroscopy. Studies using DEMS [28-37], electrochemical thermal desorption mass spectroscopy (ECTDMS) [71], and multipurpose electrochemical mass spectrometry studies (MPEMS) [29] have drawn the conclusion that all mono- or bi-aliphatic alcohols, except tertiary ones, yield minor amounts of $\mathrm{CO}_{2}$ with the corresponding aldehydes or keto-compounds as major products during their electro-oxidation. Typically, on-line DEMS, especially under well-defined transport and diffusion conditions, has the ability to quantitatively determine kinetic parameters (reaction orders, activation energies, steady-state rates) for the overall EOR, and also for the partial reactions leading to the individual reaction products such as $\mathrm{CO}_{2}$, acetic acid, and acetaldehyde [16,30-33,35,72].

By combining cyclic voltammetry and potential step measurements of the reaction transients with DEMS, Behm and co-workers performed a thorough investigation on the EOR products on a carbon-supported Pt nanoparticle catalyst at reaction temperature $\left(23-60{ }^{\circ} \mathrm{C}\right)$ [30], and on $\mathrm{PtRu}$ and $\mathrm{Pt}_{3} \mathrm{Sn}$ catalysts [33]. Absolute rates for $\mathrm{CO}_{2}$ and acetaldehyde formation were determined via the doubly ionized carbon dioxide at $\mathrm{m} / \mathrm{z}=22$ and the $\mathrm{CHO}^{+}$fragment at $\mathrm{m} / \mathrm{z}=29$ from the calibrated mass spectrometric currents, whereas acetic acid yields were determined indirectly by calculating the difference between the measured Faradaic current and the partial currents of ethanol oxidation to $\mathrm{CO}_{2}$ and acetaldehyde. More importantly, they convincingly showed that Pt-based catalysts exhibit selectivity towards $\mathrm{CO}_{2}$ ranging from $0.5 \%-7.5 \%$, which is far below the selectivity needed for economic implementation of the DEFC technology. They further explored the reaction in a wider temperature range (up to $100{ }^{\circ} \mathrm{C}$ ) and found that the current efficiency for $\mathrm{CO}_{2}$ formation increased 
significantly with the temperature while it decreased with increasing potential [37]. The latter observation suggests that the rate limiting step was changed from $\mathrm{CO}_{\text {ad }}$ oxidation at lower potential to $\mathrm{C}-\mathrm{C}$ bond breaking at higher potentials. This transition is reasonable because the cleavage of the $\mathrm{C}-\mathrm{C}$ bond becomes vital when the surface has the ability to easily remove poison species at higher potentials.

\subsection{Theoretical Studies}

Over the past decade the theoretical description of surface reactions has undergone a radical development $[38,39]$. Advances in density functional theory make it now possible to describe catalytic reactions on surfaces with the detail and accuracy required, so that computational results compare favorably with experiments. Simulations and theoretical studies have helped to advance our understanding of the EOR including predictions of vital intermediates, the preferable pathway, or the underlying electron transport process [40-42]. Some of these theoretical works corroborate with works that have been proposed by experimentalists, including the confirmation of some adsorbed intermediates in the step-wise mechanism, which are not detectable, probably due to the limited time resolution of the current experimental techniques. Therefore, theoretical studies may help to reconcile controversies and to understand variations in catalytic activity from one catalyst to another [73].

A higher percentage of C1 pathway is desirable for high efficiency DEFCs, but the production of $\mathrm{CO}_{2}$ can be as low as $0.5 \%$ as shown by DEMS [31]. DFT was used to elucidate the reasons for the low efficiency of EOR on Pt [38] and the study found that a higher percentage of C1-pathway requires a careful control of oxidant surface coverage to allow facile $\mathrm{C}-\mathrm{C}$ bond cleavage. Ethanol oxidation shows significant structure sensitivity in that the defect sites activate both the $\mathrm{O}-\mathrm{H}$ and the $\mathrm{C}-\mathrm{C}$ bonds [74]. The presence of $\mathrm{OH}$ or $\mathrm{O}$ species will considerably increase the energy barrier of the $\mathrm{C}-\mathrm{C}$ bond cleavage as shown by DFT calculations, therefore the C1 pathway will be largely reduced compared to the corresponding clean surface. On a clean Pt surface with defects at low applied potentials, and thus low oxidant coverages, the formation of acetic acid and $\mathrm{CO} / \mathrm{CO}_{2}$ are energetically favorable and, interestingly, comparable. This finding is consistent with the experimental observations $[18,20,23,66]$ that CO formation is indeed reasonably facile at low applied potentials on clean Pt surfaces. Increasing the applied potential, results in increasing oxidant surface coverage and leads to a large reduction in the rate of $\mathrm{C}-\mathrm{C}$ bond cleavage. However, surface oxidants are required for conversion of $\mathrm{CO}$ to $\mathrm{CO}_{2}$. These two competing processes explain the inability of pure platinum catalysts to act as efficient DEFC catalysts.

There has been some debate over whether $\mathrm{C}-\mathrm{C}$ bond breaking is the rate limiting step in EOR. Very recently Anderson's group calculated the reversible potentials for the reaction intermediates of EOR on Pt (111) [45] using DFT. They found that surface potentials for the path to $\mathrm{CO}_{2}$ were low and close to the calculated $0.004 \mathrm{~V}$ reversible potential for the 12 electron oxidation of ethanol. The main activation energy in the total oxidation of ethanol to $\mathrm{CO}_{2}$ comes from the formation of $\mathrm{OH}_{\text {ads }}$ from $\mathrm{H}_{2} \mathrm{O}$ with a reversible potential of $0.49 \mathrm{~V}$, the highest potential as shown in Figure 5. The favorable path to $\mathrm{CO}_{2}$ takes the right hand branch to $\mathrm{OCCH}_{3}$ and then to $\mathrm{OCCH}_{\text {ads }}$ [45]. $\mathrm{OH}_{\text {ads }}$ is essential for the oxidation of $\mathrm{CO}_{\text {ads }}$ and $\mathrm{CH}_{\text {ads, }}$ which leaves $\mathrm{OH}_{\text {ads }}$ formation to be the rate limiting step. Accordingly, an ideal catalyst would have the ability to adsorb most intermediates weakly but $\mathrm{OH}$ more strongly. This 
conclusion agrees with the observation that the maximum rate of adsorbed acetyl decomposition into COads and $\mathrm{CH}_{x}$, ads appeared at 0.3-0.4 V vs. RHE [70], which is significantly lower than the onset potential of $\mathrm{OH}_{\text {ads }}$ formation $(\sim 0.5 \mathrm{~V})$ [75].

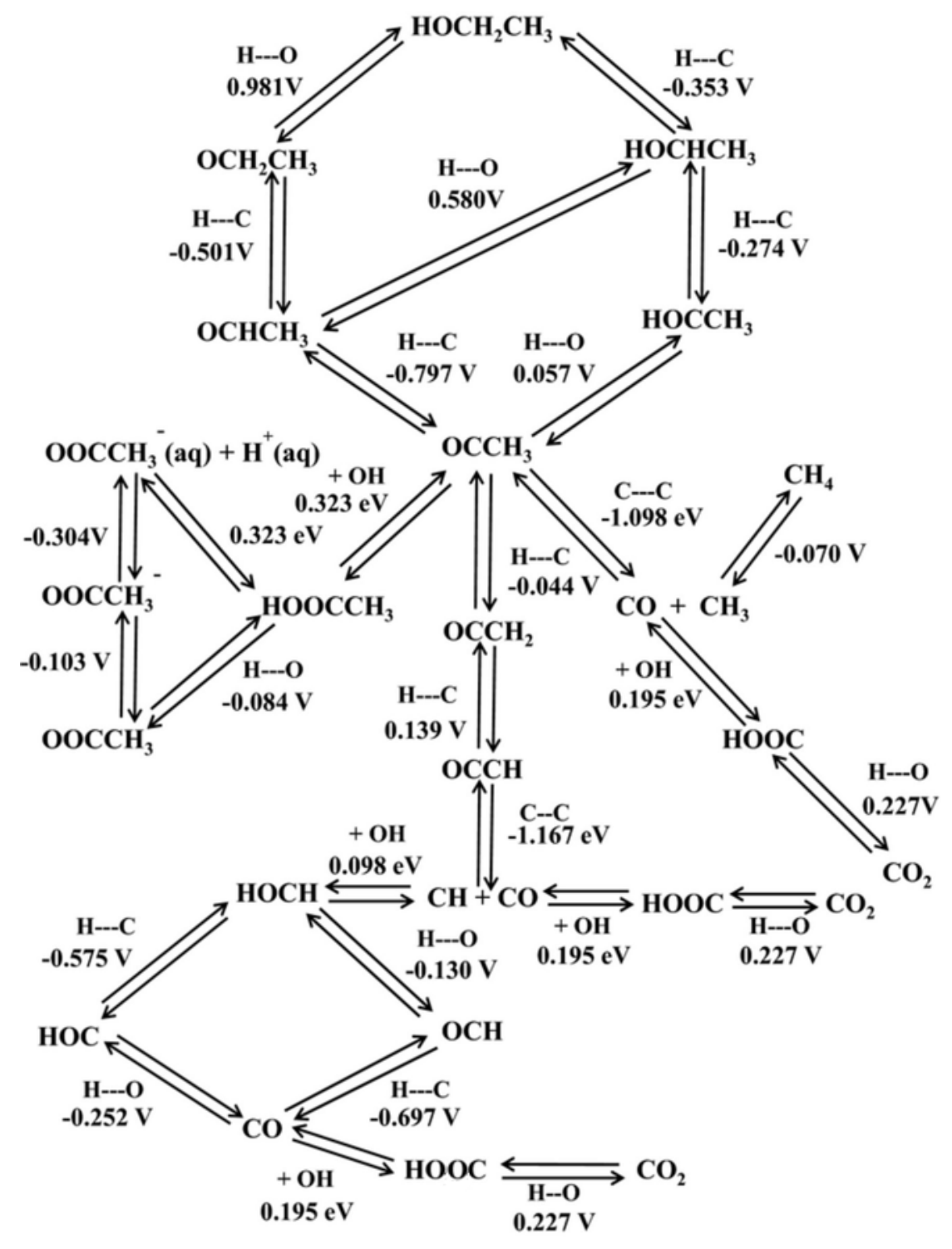

Figure 5. Reaction network calculated for ethanol electro-oxidation to $\mathrm{CO}_{2}$, methane, and acetate. Reproduced with permission from Reference [45]. Copyright 2015, the Electrochemical Society.

The role of water and hydroxyls during EOR on Pd electrodes in alkaline media was further investigated by Lin's group [39] by acquiring first principle calculations. The possible pathways for the formation of acetate from acetaldehyde were evaluated by comparing the reaction barriers $\left(E_{\mathrm{a}}\right)$ as well as thermodynamic $(\Delta E)$ and structural parameters. Their results suggested that acetaldehyde is first hydrated in water to form germinal diol, and then the dehydrogenation of germinal diol produces acetate. According to this study, the $\mathrm{OH}^{-}$anion acts as the center in the concerted-like dehydrogenation path as shown in Figure 6 confirming what has been found in experiments. 


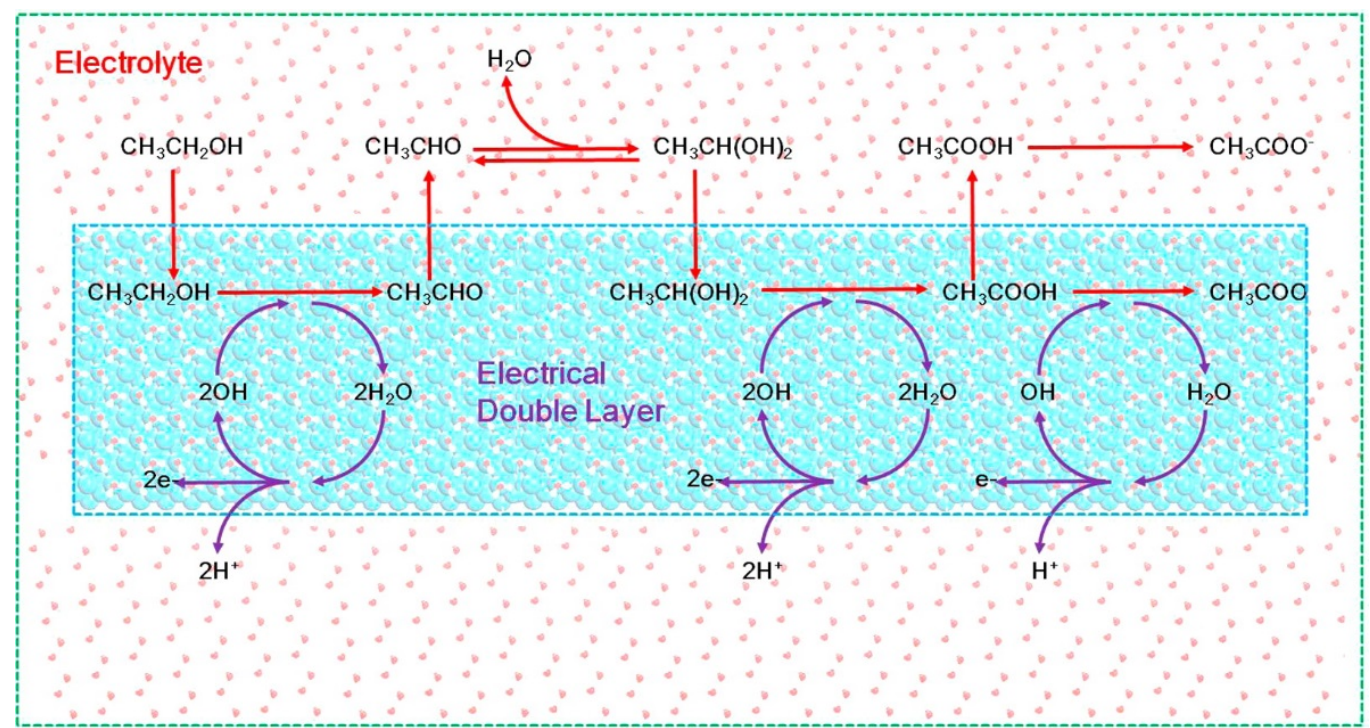

Figure 6. General scheme describing the ethanol oxidation reaction on Pd electrodes in the presence of an electrical double layer proposed by first principle calculations. Reproduced with permission from Reference [39]. Copyright 2014, American Chemical Society.

The total oxidation current at lower potentials was found to be rather structure sensitive where the presence of steps enhances the rupture of the $\mathrm{C}-\mathrm{C}$ bond and the complete oxidation to $\mathrm{CO}_{2}$ [74]. Theoretical studies have identified the platinum monoatomic steps as the most likely sites for full ethanol oxidation and concluded that the close-packed surfaces are unsuitable [76]. Liu's group [43,44] clarified the location of the transition state and saddle points for most surface reactions during EOR on different Pt surfaces based on gradient-corrected DFT as shown in Figure 7. Their results suggest the EOR is a structure-sensitive reaction that is influenced by two key reaction steps: (i) the initial dehydrogenation of ethanol and (ii) the oxidation of acetyl $\left(\mathrm{CH}_{3} \mathrm{CO}\right)$. By simulating three typical $\mathrm{Pt}$ surfaces, namely close-packed Pt (111), monatomic stepped Pt (211), and open Pt (100), these authors demonstrated for the first time that the selectivity of ethanol oxidation on Pt is highly structure sensitive among which Pt (100) is the best surface to fully oxidize ethanol to $\mathrm{CO}_{2}$ at low coverages. It shows that $\mathrm{CO}_{2}$ and acetic acid originate from the same surface intermediate i.e., $\mathrm{CH}_{3} \mathrm{CO}$ as experimentally evidenced by our group [23], but acetaldehyde is from ethanol directly. The cleavage of the $\mathrm{C}-\mathrm{C}$ bond occurs through the strongly chemisorbed precursor $\mathrm{CH}_{2} \mathrm{CO}$ or $\mathrm{CHCO}$ only at low-coordinated surface sites, not from $\mathrm{CH}_{3} \mathrm{CO}$ as proposed by FTIR study [13,14]. Acetaldehyde is produced via the one-step concerted dehydrogenation of ethanol, which occurs mainly on close-packed (111), and is enhanced by increased $\mathrm{CH}_{\mathrm{x}}$ coverage. Acetic acid is the dominant oxidation product on $\mathrm{Pt}(111)$ at oxidative conditions, but its formation is significantly inhibited by the monoatomic steps.

In summary, EOR is a very complex reaction that can proceed via different pathways. The product distribution and the dominant reaction pathway depend on many factors including temperature, catalyst material and structure, applied potential, ethanol concentration, reaction media, etc. [20,30-32,37,45-47]. The interplay of these factors affects EOR greatly. Typically, the adsorption of hydroxyl is vital in both acidic and alkaline media [18,39,40,45-47]. In acidic media, at low potentials $\mathrm{C}-\mathrm{C}$ bond cleavage occurs readily to form CO $[30,43]$. Owing to the unavailability of oxidants to remove $\mathrm{CO}_{\text {ads, }}$ the 
surface is poisoned and $\mathrm{CO}_{2}$ production is limited. At higher potentials, there are abundant oxidants, but $\mathrm{C}-\mathrm{C}$ bond cleavage is inhibited by the high coverage of oxidants, thus leading again to small $\mathrm{CO} / \mathrm{CO}_{2}$ production [45]. Similarly in alkaline media, the dissociative adsorption of ethanol proceeds rather quickly and the rate-determining step is the removal of the adsorbed species, which varies among literature, by the adsorbed hydroxyl. At higher potentials the kinetics is not only affected by the electro-adsorption of $\mathrm{OH}^{-}$ions, but also by the formation of the inactive surface oxide layer [20,23,39]. Therefore EOR on Pt- or Pd-based catalysts proceeds predominantly with the C2 pathway and acetic acid or acetate is the main product. Carbon dioxide or carbonate is relatively low in the product distribution [3,30,37,57]. In general EOR proceeds through similar reaction pathways but some differences have been discussed. In acidic media, the initial bond breaking step is dehydrogenation at $\alpha$-carbon, while in strong alkaline media it is the $\mathrm{O}-\mathrm{H}$ bond cleavage $[18,20,43,45]$.
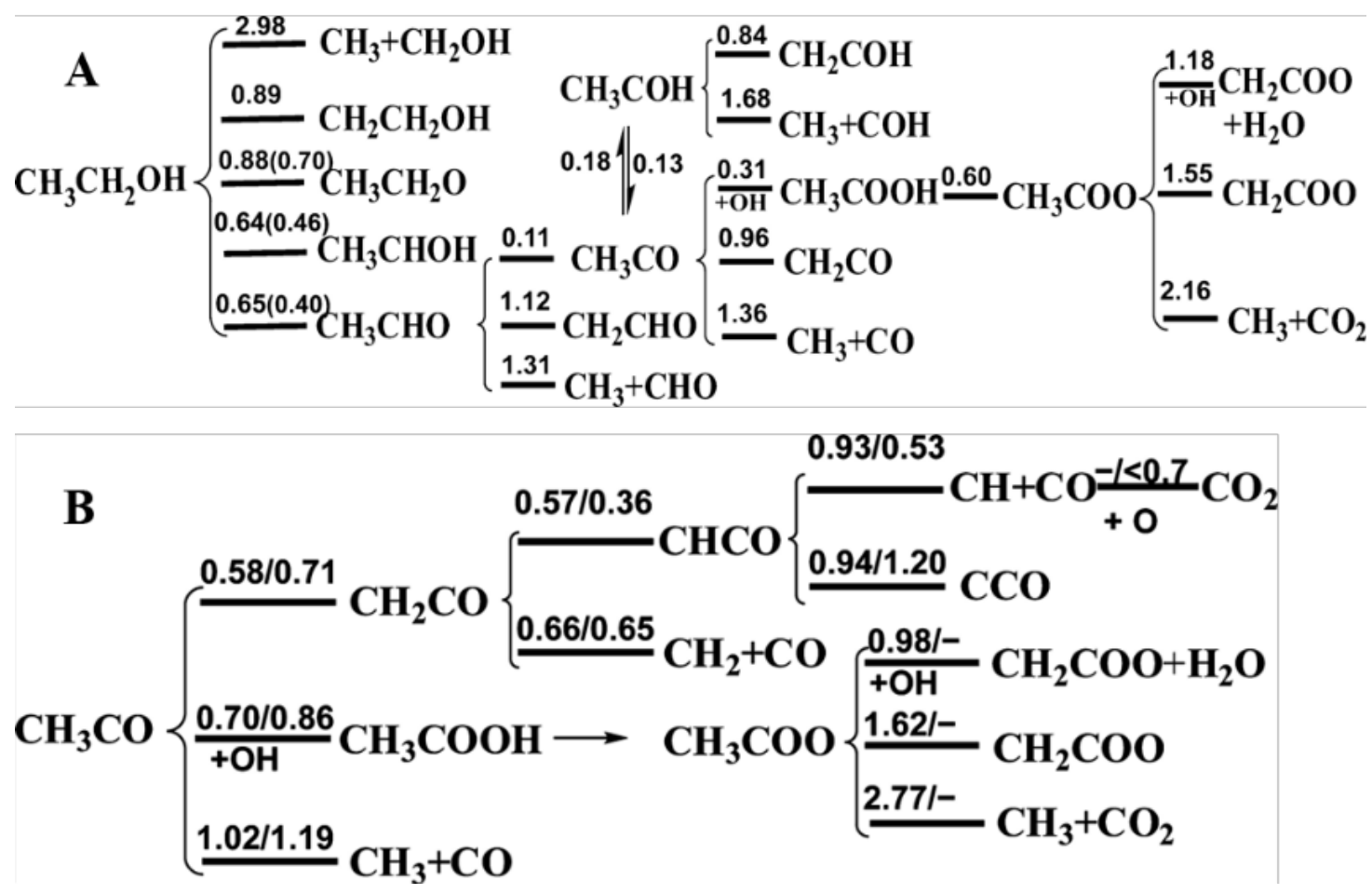

Figure 7. Calculated reaction network and reaction barriers (units, eV) for ethanol oxidation (A) on Pt (111) and acetyl oxidation (B) on Pt (211) (data on the left) and Pt (100) (data on the right). Reprinted and adapted with permission from Ref. [43]. Copyright 2008, American Chemical Society.

Despite the diverse reaction mechanisms for EOR presented in the literature, some characteristics of a highly efficient catalyst for complete oxidation of ethanol to $\mathrm{CO}_{2}$ have emerged. The rationally designed catalysts would have: (i) suitable surface sites for $\mathrm{C}-\mathrm{C}$ bond breaking; (ii) a suitable surface composition to increase selectivity for $\mathrm{CO}_{2}$ formation; (iii) a bifunctional effect to facilitate the adsorption and activation of water to form $\mathrm{OH}_{\text {ads }}$ for the removal of $\mathrm{CO}$ and $-\mathrm{CH}_{x}$ species [45,76]. Utilizing these design guidelines, researchers have developed many new catalysts with higher selectivity and activity, and longer durability as demonstrated in the following studies. 


\section{Catalytic Role of the Electrode Materials}

As discussed above, both experimental and theoretical studies suggest that the lower electro-efficiency C2 pathway is the dominant for EOR on Pt and Pd surfaces. Therefore a good tactic to obtain a better electrocatalytic performance is to increase the ratio of C1 to C2 pathway to achieve a more complete ethanol oxidation, which as shown above requires active surface sites for $\mathrm{C}-\mathrm{C}$ bond breaking, $\mathrm{CO}$ and $-\mathrm{CH}_{x}$ species removal together with a suitable surface structure to increase selectivity for $\mathrm{CO}_{2}$ formation [77]. Moreover, $\mathrm{C} 1$ pathway always involves the participation of water or its adsorption residue, a good electrocatalyst must be able to activate both ethanol and water adsorption, which can be achieved by varying the composition and structure of the rationally designed catalysts. In the following we first summarize some design principles and then use selected examples to elucidate the applications of these principles to obtain high performance catalysts.

\subsection{Principles in Rational Design}

Electronic effect: when Pt or Pd is alloyed or modified with another metal, the electronic interaction between Pt or Pd and the other metal results in the changes in their valence electronic structure through ligand effect and strain effect which can be described as the shift in the d-band center $\left(\varepsilon_{\mathrm{d}}\right)$ as proposed by Norskov and co-workers [50,73,78,79] and reviewed by Demirci [10]. The d-band center directly relates to the binding energy of surface poison or reactive intermediates. A higher-lying $\varepsilon_{\mathrm{d}}$ suggests a more reactive surface that tends to bind adsorbates more strongly while a surface with a lower-lying $\varepsilon_{\mathrm{d}}$ tends to bind adsorbates more weakly and facilitates the formation of bonds among them. In the EOR mechanism mentioned above, a suitable $\varepsilon_{\mathrm{d}}$ with a moderate binding energy of $\mathrm{CO}, \mathrm{CH}_{x}$, and acetyl or acetaldehyde, but higher energy for $\mathrm{OH}$ binding is needed by adjusting the electronic effect.

A bifunctional effect originates from Pt-Ru alloys and is extended to $\mathrm{Pt} / \mathrm{Sn}$ and $\mathrm{Pt} / \mathrm{SnO}_{x}$ [1]. In this mechanism, the presence of $\mathrm{Ru}, \mathrm{Sn}$, or $\mathrm{SnO}_{x}$ aids in the activation of water dissociation to form surface hydroxides, which can more readily oxidize $\mathrm{CO}$ and $\mathrm{CH}_{x}$ intermediates and therefore exhibit relatively higher EOR performance [80]. These alloys also tend to promote the partial oxidation of acetaldehyde to acetic acid. However, catalysts with a bifunctional effect do not particularly enhance $\mathrm{C}-\mathrm{C}$ bond cleavage during EOR [81].

Surface-structure effect is another important parameter that significantly changes the activity of catalysts. EOR is a surface sensitive reaction and its efficiency largely depends on the crystal orientation of the catalyst surface [48]. In alkaline media Pt(111) electrodes display the highest current and lowest onset oxidation potential, however with little $\mathrm{CO}_{2}$ production. On the other hand, $\mathrm{Pt}(100)$ electrodes are considered to be more active in the breaking of $\mathrm{C}-\mathrm{C}$ bond and the formation of CO $[43,48]$ no matter whether acidic or alkaline media. Construction of Pt or Pd based catalysts with well-defined morphology and a tunable surface is therefore another way to gain higher electrocatalytic performance catalysts. 


\subsection{Pt and Pd Based Electrocatalysts}

\subsubsection{Pt Based Catalysts}

Previous studies have shown a monometallic catalyst such as Pt exhibits a selectivity of oxidation of ethanol to $\mathrm{CO}_{2}$ of $0.5 \%-7.5 \%$ in acidic media [30], which falls short for the commercialization of DEFCs. Pure Pt can easily be poisoned by intermediates (including CO) generated during EOR. Regardless of the media, Pt-based materials represent the benchmark catalysts for ethanol oxidation. Elements such as $\mathrm{Ru}$ [32,33,35,60,82,83], Sn [15,32,33,35,80,84-86], Pb [21,87-91], Bi [36,89,90,92,93], Re[86], Sb[93], Ir [94], Au [95], Ce [96], Rh [81,97], Pd [81,98,99], Fe [100], Ni [95,101], P[102], Mo [83,103] have been widely employed to enhance the activity and selectivity. In addition, metal oxides, such as $\mathrm{MgO}, \mathrm{CeO}_{2}, \mathrm{ZrO}_{2}, \mathrm{SnO}_{x}[76,94,104] \mathrm{RuO}_{2}, \mathrm{PbO}_{x}$ [88] have also been investigated for facilitating the removal of $\mathrm{CO}$. The enhancement has been attributed to the steric hindrance of the surface, or electronic and/or bifunctional effects when the adatoms are directly involved in the catalytic process.

Up to now, PtRu [32,33,35,60,82,83] and PtSn [15,32,33,35,80,84-86] have been regarded as some of the most efficient catalysts for EOR according to the bifunctional effects. The distribution of products is well-studied by FTIR [35] and DEMS [33,35,55]. The addition of Sn or Ru, though beneficial for the overall activity of EOR, and the partial oxidation of acetaldehyde to acetic acid, does not enhance the activity for $\mathrm{C}-\mathrm{C}$ breaking [35]. The higher current is mainly contributed from the higher yields of $\mathrm{C} 2$ products. These alloys aid in the oxidation of CO but actually lower the total conversion to $\mathrm{CO}_{2}$ because they slow down the breaking of the $\mathrm{C}-\mathrm{C}$ bond. Because Pt is the active metal for $\mathrm{C}-\mathrm{C}$ bond activation, alloying decreases the amount of $\mathrm{Pt}$ and its ability to activate the $\mathrm{C}-\mathrm{C}$ bond.
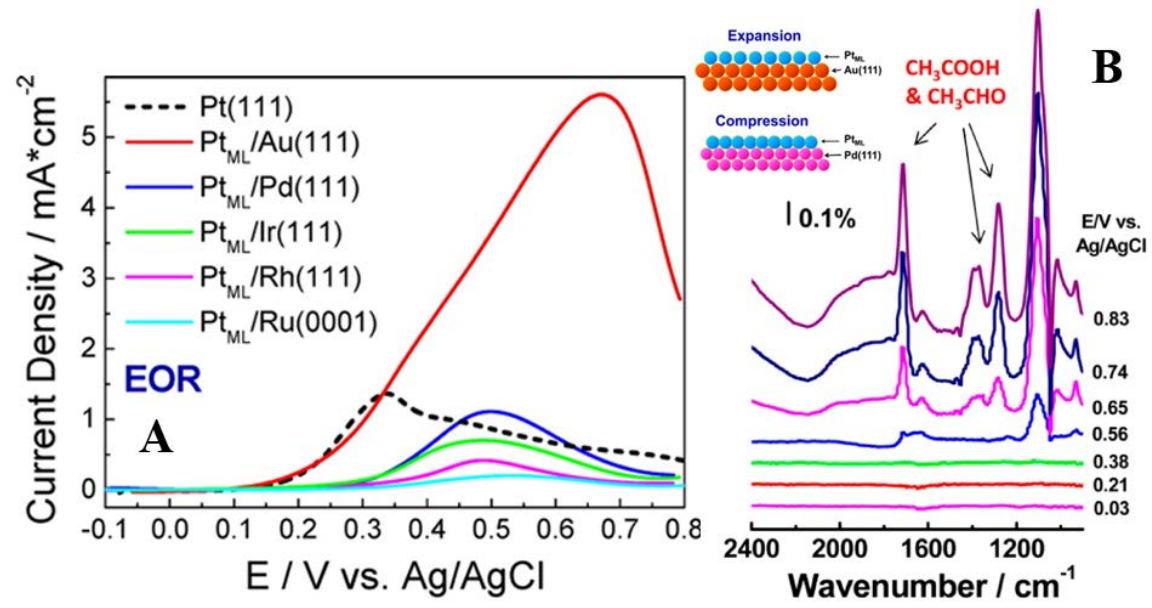

Figure 8. (A) Positive voltammetric scans for Pt(111) and PtmL supported on five different substrates in $0.1 \mathrm{M} \mathrm{HClO} 4$ containing $0.5 \mathrm{M}$ ethanol; (B) In situ infrared reflection-absorption spectroscopy (IRRAS) spectra recorded during EOR on the $\mathrm{Pt}$ LL/Au(111) electrode in 0.1 $\mathrm{M} \mathrm{HClO}_{4}$ containing $0.5 \mathrm{M}$ ethanol. Inserted are models of pseudomorphic monolayers of Pt on two different substrates of $\mathrm{Au}(111)$ and $\mathrm{Pd}(111)$. Reprinted and adapted with permission from Reference [105]. Copyright 2012, American Chemical Society. 
To further promote selectivity and activity of EOR, Adzic's group developed Pt monolayer (PtML) electrocatalysts comprising a one atom thick layer of Pt placed on selected extended or nanoparticle surfaces. They observed a correlation between substrate-induced lateral strains in the Pt monolayer and its activity/selectivity towards EOR. In agreement with previous theories [10,73], a positive- or tensile-surface strain in the metal overlayer tends to upshift $\varepsilon_{\mathrm{d}}$ and therefore facilitates $\mathrm{OH}_{\text {ads }}$ formation resulting in an enhanced EOR as shown in Figure 8. The IRRAS spectra showed that acetic acid is the predominant product [105]. This work demonstrates nicely the importance of electronic effect in tuning electrocatalytic activity.

Along this line, various Pt-Au alloys have been proposed and have shown relatively high EOR performance [41,106]. Recently Pt-Au hetero-nanostructures were synthesized by varying the reduction kinetics of a gold precursor to obtain dimer Pt-Au or core-satellite (Pt@Au) structures. These catalysts show high selectivity and improved efficiency in alkaline media compared to their monometallic counterparts [107].

Ternary nanoalloys incorporating suitable metal and metalloid components are expected to exhibit more flexibility in tuning the geometric and electronic properties of Pt surfaces, thus are promising to achieve a higher electrocatalytic performance. Adzic's group found the ternary-electrocatalysts, Pt-Rh-SnO $/$ C $[9,76]$ can effectively split the $\mathrm{C}-\mathrm{C}$ bond in ethanol at room temperature in acidic solutions and the highest activity was obtained with a composition of Pt:Rh:Sn = 3:1:4 [9]. As shown in Figure 9, the integrated band intensities of $\mathrm{CO}_{2}\left(2343 \mathrm{~cm}^{-1}\right), \mathrm{CH}_{3} \mathrm{CHO}\left(933 \mathrm{~cm}^{-1}\right)$, and $\mathrm{CH}_{3} \mathrm{COOH}\left(1280 \mathrm{~cm}^{-1}\right)$ for both $\mathrm{Pt}-\mathrm{Rh}-\mathrm{SnO}_{2} / \mathrm{C}$ and $\mathrm{Pt}-\mathrm{SnO}_{2} / \mathrm{C}$ samples proved the enhanced cleavage of the $\mathrm{C}-\mathrm{C}$ bond in ethanol and all three constituents $\mathrm{Pt}, \mathrm{Rh}$, and $\mathrm{SnO}_{2}$ are needed to gain the synergistic effect in facilitating the total oxidation of ethanol.
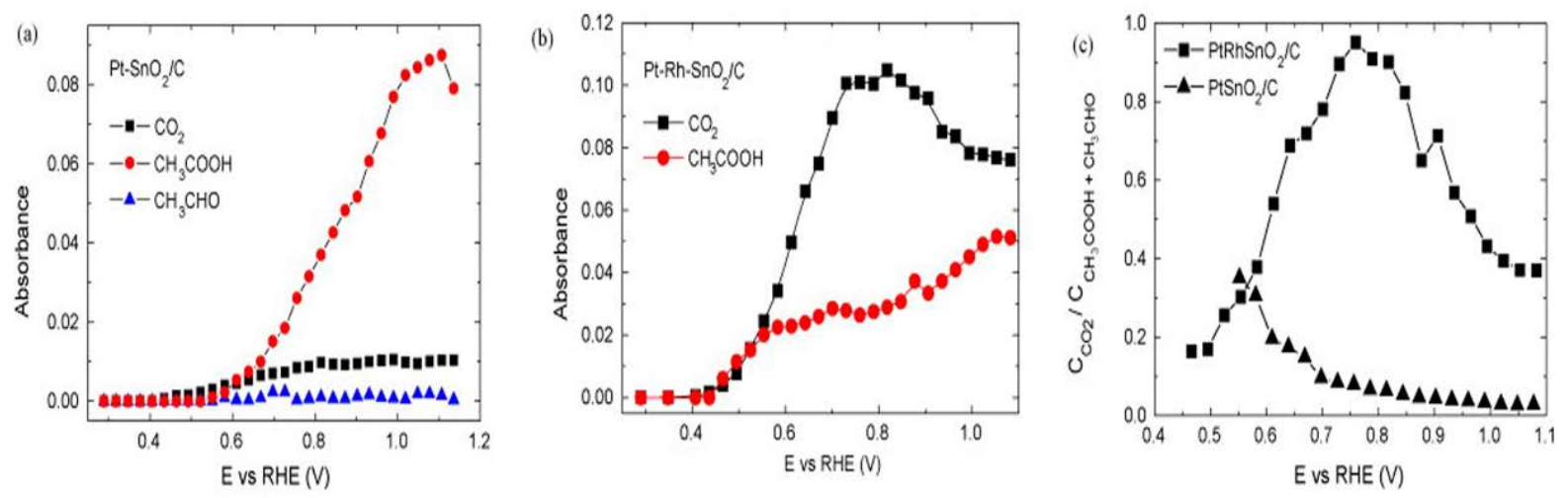

Figure 9. Integrated band intensities of $\mathrm{CO}_{2}, \mathrm{CH}_{3} \mathrm{CHO}$ and $\mathrm{CH}_{3} \mathrm{COOH}$ in IRRAS spectra from (a). $\mathrm{Pt}-\mathrm{SnO}_{2} / \mathrm{C}$ with the atomic ratio $\mathrm{Pt}: \mathrm{Sn}=3: 4$; (b). $\mathrm{Pt}-\mathrm{Rh}-\mathrm{SnO}_{2} / \mathrm{C}$ with the atomic ratio Pt:Rh:Sn = 3:1:4; (c) The charge ratio of the total oxidation pathway $\left(\mathrm{CCO}_{2}\right)$ over the partial oxidation pathway $\left(\mathrm{C}_{\mathrm{CH}_{3} \mathrm{COOH}}+\mathrm{C}_{\mathrm{CH}_{3} \mathrm{CHO}}\right)$ as a function of electrode potential for both electrocatalysts in $0.1 \mathrm{M} \mathrm{HClO}_{4}$ and $0.1 \mathrm{M}$ ethanol. Reprinted and adapted with permission from Reference [9]. Copyright 2010, Elsevier.

Electrode arrays of 91 combinations of Pt-Sn-M (M = Fe, Ni, Pd, and Ru) were prepared and screened by a fluorescence assay (Figure 10) to optimize the catalysts with the highest electrocatalytic activity by Abruña and co-workers [101]. They found that Fe-containing catalysts exhibited the highest 
activity followed by $\mathrm{Ni}$ - and Pd-containing materials with similar results. This work shows that the variation and combination of different components can exert better electro-activity performance with different electronic effects.

EOR strongly depends on the electronic and surface structures of the catalysts. The different EOR activities observed on Pt surfaces with different crystallographic orientations offer the possibility of optimizing activities of nanoscale practical catalysts by controlling the particle shape $[48,49,74]$. By using cubic Pt nanoparticles, on which (100) surface sites are predominant, the performance of DEFCs can be increased from 14-24 $\mathrm{mW}$ per $\mathrm{mg}$ of $\mathrm{Pt}$ when compared with cuboctahedral nanoparticles. Moreover, the open circuit potential shifts about $50 \mathrm{mV}$ toward more positive potentials [108]. Pt nanoparticles with 24 high-index facets such as (730), (210), and/or (520) surfaces were synthesized and showed enhancement on EOR compared with commercial $\mathrm{Pt} / \mathrm{C}$ as well as a higher selectivity for the cleavage of the C-C bond [109].
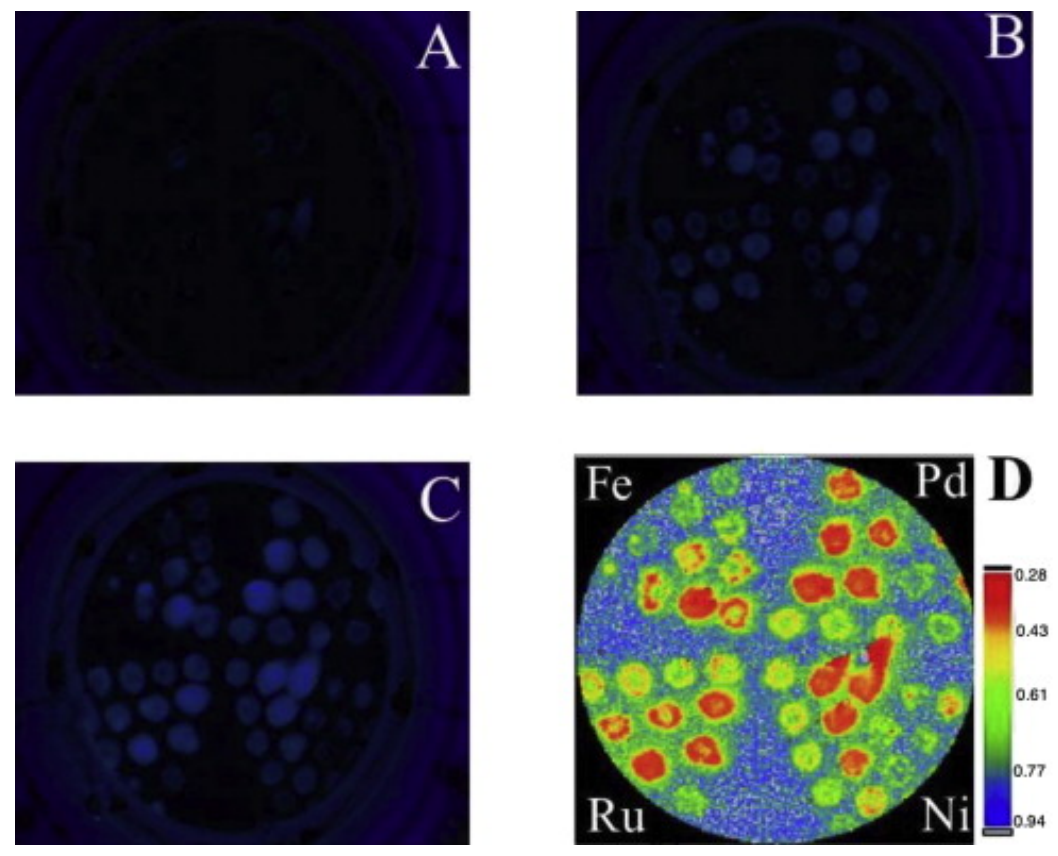

Figure 10. Combinatorial array and screening results by fluorescence imaging of PtSnM electrode arrays in 6.0 M ethanol and quinine fluorescent indicator. Active compositions for ethanol electro-oxidation are shown as bright spots: fluorescence image at (A) lower overpotential ( $\sim 0.27 \mathrm{~V}$ vs. RHE); (B) intermediate overpotential ( 0.46 V vs. RHE) and (C) high overpotential ( $\sim 0.93 \mathrm{~V}$ vs. RHE); (D) Fluorescence onset potential for ethanol electro-oxidation on PtM and PtSnM library. Reproduced with permission from Reference [101]. Copyright 2015, Elsevier.

Bimetallic or ternary nanocrystals have also been studied to explore the optimal combination of higher activity surface facets and electronic effect. The composition-varied (100)-terminated Pt-Pd-Rh nanocubes (NCs) and (111)-terminated Pt-Pd-Rh nanotruncated-oxtahedrons (NTOs) were synthesized with the help of halides [81]. Owing to the synergistic effects resulted from appropriate surface composition and exposed facets, the Pt-Pd-Rh NTOs exhibited the highest selectivity to $\mathrm{CO}_{2}$ and PtPdRh NCs possessed the best durability. With the help of in situ FTIR and DFT calculations, the 
influence of the exposed facet and surface composition on the capability of $\mathrm{C}-\mathrm{C}$ bond cleavage was examined. It was found that (100)-bounded surface is favorable to the cleavage of $\mathrm{C}-\mathrm{C}$ bond while (111)-bounded surface tends to oxidize CO more easily.

\subsubsection{Pd Based Catalysts}

There has been a surge of interest in developing Pd-based catalysts mainly because facile EOR kinetics are expected in alkaline media on the less costly and more abundant Pd $[17,47,66]$. However, Pd itself cannot meet the practical demand because of shortage of activity and durability. In particular, a great deal of interest has been focused on the use of Pd-based alloy catalysts as an alternative for EOR where the catalytic activity may be further increased by the addition of a second metal or metal oxide promoters through the effects mentioned above. Various Pd-based catalysts have been synthesized with the addition of one or more elements including $\mathrm{Ni}$ [110,111], Ag [112,113], $\mathrm{Au}$ [114-116], P [117], Co [118], Sn [80,110,119,120], Ru [53], Zn [121] as well as metal oxides like $\mathrm{SnO}_{2}, \mathrm{CeO}_{x}, \mathrm{Co}_{3} \mathrm{O}_{4}, \mathrm{Mn}_{3} \mathrm{O}_{4}, \mathrm{NiO}[102,122-125]$ or on various substrates like graphene [126], carbon microspheres [127], nanowire [128], carbon fiber [118], etc.

Sn can promote the catalytic activity of Pd toward EOR by providing oxygen-containing species at more negative potentials due to the bifunctional effect and electronic effects, and has therefore been widely studied [80,119,120]. Teng's group synthesized carbon supported Pd-Sn electrocatalysts with different amounts of Sn, and determined that the optimum Sn content in Pd-Sn for EOR was 14\%. The promotional effect of Sn on EOR activity was confirmed by kinetic study and DFT calculations [80]. The reaction energies of the initial steps of EOR ( $\mathrm{H}$ removal) were studied with several catalysts using DFT (a Pd surface, a Pd-Sn1, and a Pd-Sn5 surface) in this work. As shown in Figure 11, Pd-Sn alloy structures resulted in lower reaction energies for the dehydrogenation of ethanol compared to pure Pd. Despite that the DFT calculations in reference [80] only involve the initial steps of EOR, their experimental results support the premise that Pd-Sn may be a better catalyst than Pd for EOR.
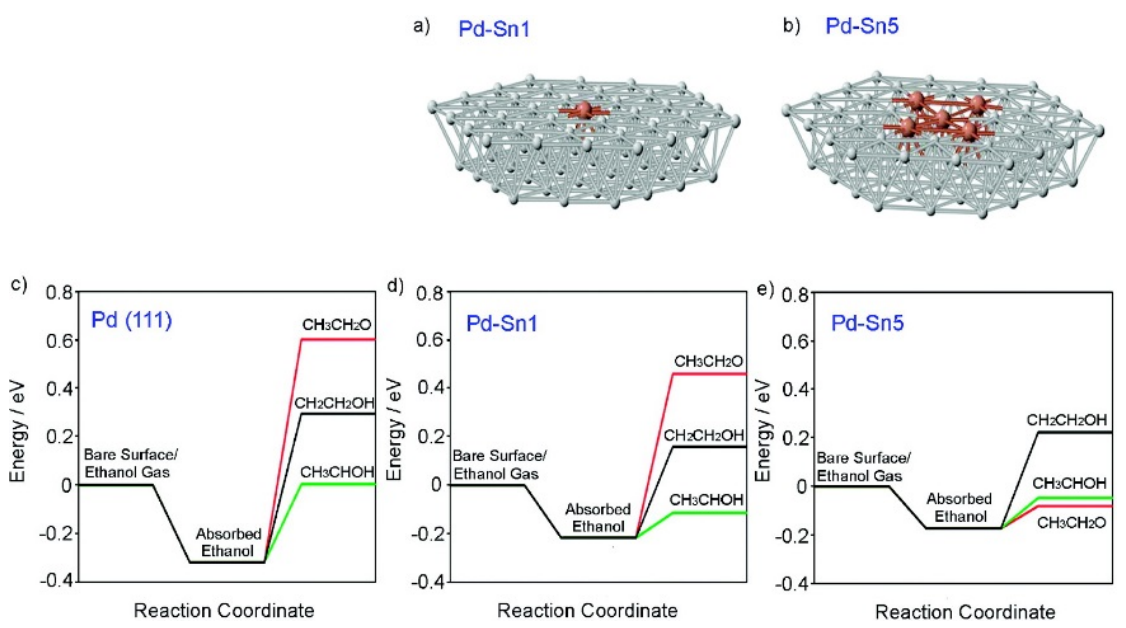

Figure 11. Surface cluster models of (a) $\mathrm{Pd}-\mathrm{Sn}_{1}$ and (b) $\mathrm{Pd}-\mathrm{Sn}_{5}$ used for modeling ethanol dehydrogenation, and reaction energies for $\mathrm{H}$ removal from ethanol over (c) Pd (111); (d) $\mathrm{Pd}-\mathrm{Sn}_{1}$, (e) $\mathrm{Pd}-\mathrm{Sn}_{5}$ surfaces. Reproduced with permission from Reference [80]. Copyright 2012, American Chemical Society. 
$\mathrm{Au}$ is another promising candidate for promoting EOR on Pd catalysts. Zhao's group [114] synthesized a monolayer or a sub-monolayer of Pd adatoms decorated on $\mathrm{Au} / \mathrm{C}$ with different $\mathrm{Pd}: \mathrm{Au}$ atomic ratios in the precursors via a chemical epitaxial growth method and found $\mathrm{Pd}_{1} \mathrm{Au}_{4}$ shows the highest specific activity due to the electronic effect between the Au support and the Pd decoration, and the enhanced poison resistance. To further tune the electronic and geometric effect of the catalysts, ternary catalysts PdNiAu [116] were synthesized which possessed a peak power density about three times that of the monometallic Pd catalyst, and twice that of the bimetallic PdNi catalyst. A relatively preferable $\mathrm{C} 2$ pathway on the $\mathrm{Pd}-\mathrm{Au}-\mathrm{Ni}$ catalyst compared to its single and binary counterparts in alkaline media was estimated by ion chromatography.

Doping of various oxides to Pd catalysts is another strategy to enhance the efficiency of EOR. $\mathrm{Xu}$ et al. [124] demonstrated that the addition of oxides such as $\mathrm{CeO}_{2}, \mathrm{NiO}, \mathrm{Co}_{3} \mathrm{O}_{4}$, and $\mathrm{Mn}_{3} \mathrm{O}_{4}$ significantly promoted catalytic activity and stability. Most importantly these oxides have the ability to lower the onset potential for EOR. A recent study showed a maximum energy efficiency of about 7\% from room temperature air breathing DEFCs with $\mathrm{Pd}$ on a mixed $\mathrm{CeO}_{2}-\mathrm{C}$ support as the anode catalysts [125]. The use of a mixed carbon- $\mathrm{CeO}_{2}$ support extends the stability of the Pd catalyst under working conditions by promoting ethanol electro-oxidation at lower anode potentials.
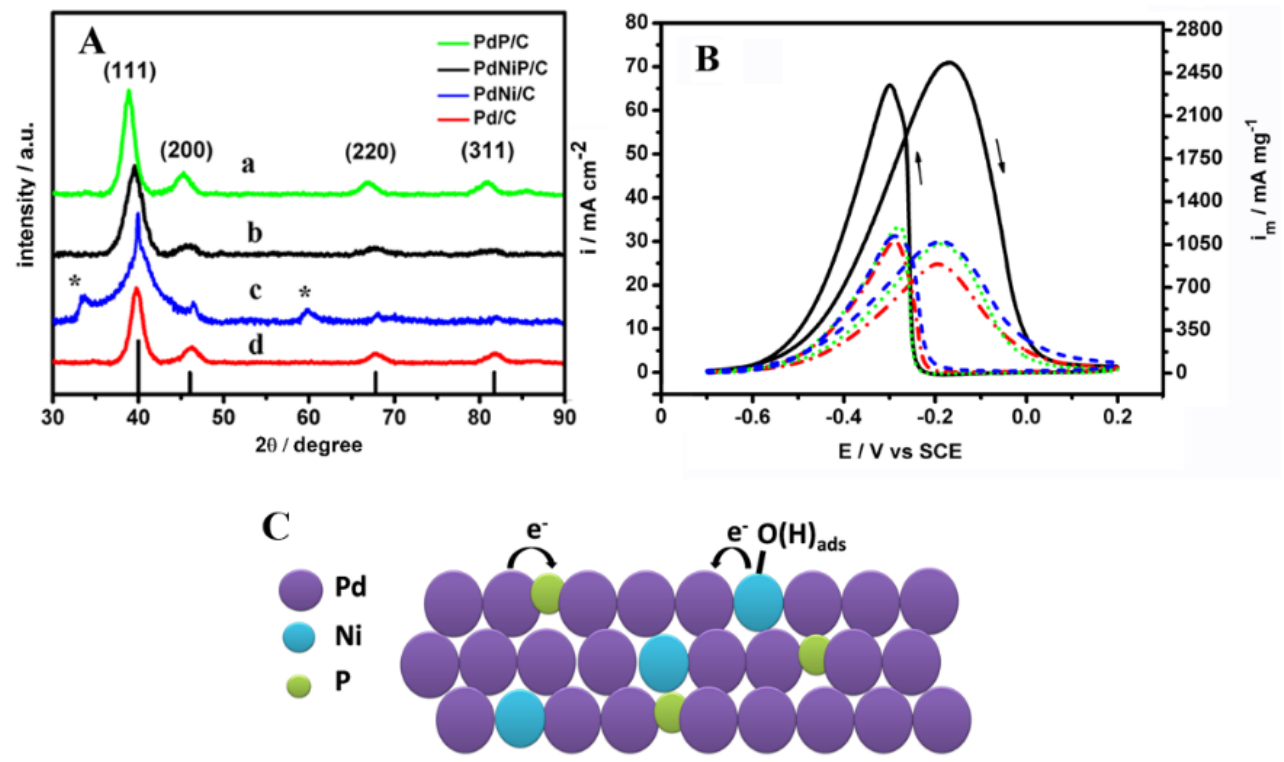

Figure 12. (A) XRD patterns of the $\mathrm{Pd}-\mathrm{P} / \mathrm{C}$ (curve a), $\mathrm{Pd}-\mathrm{Ni}-\mathrm{P} / \mathrm{C}$ (curve b), $\mathrm{Pd}-\mathrm{Ni} / \mathrm{C}$ (curve c) and $\mathrm{Pd} / \mathrm{C}$ (curve d). (B) Cyclic voltammograms for Pd-based catalysts in $0.5 \mathrm{M}$ $\mathrm{NaOH}$ and $1 \mathrm{M} \mathrm{C}_{2} \mathrm{H}_{5} \mathrm{OH}$ at $50 \mathrm{mV} \cdot \mathrm{s}^{-1}$; (C) Scheme of Pd-Ni-P atomic arrangement. The asterisks at $33.5^{\circ}$ and $59.2^{\circ}$ mark the peaks from $\mathrm{Ni}(\mathrm{OH})_{2}(100)$ and (110) facets. Reprinted and adapted with permission from Reference [117]. Copyright 2013, Elsevier.

Nonmetal component can also play a role in the rational design of catalysts [129-132]. Recently, our group discovered that $\mathrm{Pd}-\mathrm{Ni}-\mathrm{P} / \mathrm{C}$ ternary nanocatalysts showed a remarkable enhancement towards EOR compared to $\mathrm{Pd}-\mathrm{Ni} / \mathrm{C}, \mathrm{Pd}-\mathrm{P} / \mathrm{C}$ and $\mathrm{Pd} / \mathrm{C}$ [117]. After a careful analysis of the structure and oxidation state of the catalysts, we found apparently opposite effects of alloying the elements $\mathrm{P}$ and Ni. P expands the Pd lattice with the incorporation of $\mathrm{P}$ atoms in the interstice of Pd lattice, while alloying with Ni partially replaced Pd sites with smaller Ni atoms, resulting in a contraction of the Pd 
lattice. In addition, $\mathrm{P}$ accepts electrons from the surrounding $\mathrm{Pd}$ atoms while Ni donates, resulting in a slight downshift of the Pd d-band center. Alloying Pd with Ni and P creates appropriate electronic and geometric modifications to Pd, leading to a modestly weakened adsorption of intermediates on Pd sites. In addition, the oxophilic nature of $\mathrm{Ni}$ provides $\mathrm{OH}_{\text {ads }}$ at lower potentials which facilitates the removal of surface poisons. (Figure 12).

Furthermore, by de-alloying some of the $\mathrm{Ni}$ and $\mathrm{P}$ in an electrodeposited $\mathrm{Pd}-\mathrm{Ni}-\mathrm{P}$ film, we investigated the de-alloying effect on EOR performance in alkaline media. We found that the enhancement of electrocatalytic activity does not simply originate from the increase of active surface area, but is due to the variation of relative contributions of the two pathways as evidenced by in situ infrared spectroscopic results shown in Figure 13 [24]. CO and acetate band intensities (Figure 13B,D) can be used to approximate the relative contributions of the C1 and C2 pathways. Notably, the more pronounced $\mathrm{CO}_{\mathrm{ad}}$ and acetate bands observed on the de-alloyed $\mathrm{Pd}-\mathrm{Ni}-\mathrm{P}$ film provide molecular spectral evidence supporting the assumption that suitable de-alloying can enhance both $\mathrm{C}-\mathrm{C}$ cleavage in the $\mathrm{C} 1$ pathway with $\mathrm{CO}$ formation and production of acetate in the $\mathrm{C} 2$ pathway, correlating well with the observed higher EOR current on the de-alloyed film. Furthermore, the relative intensities of the $\mathrm{CO}$ bands versus the acetate bands appeared to be much higher on the de-alloyed film as compared to those on the as-deposited film, indicating that the $\mathrm{C} 1$ pathway is relatively more favorable after the de-alloying treatment.
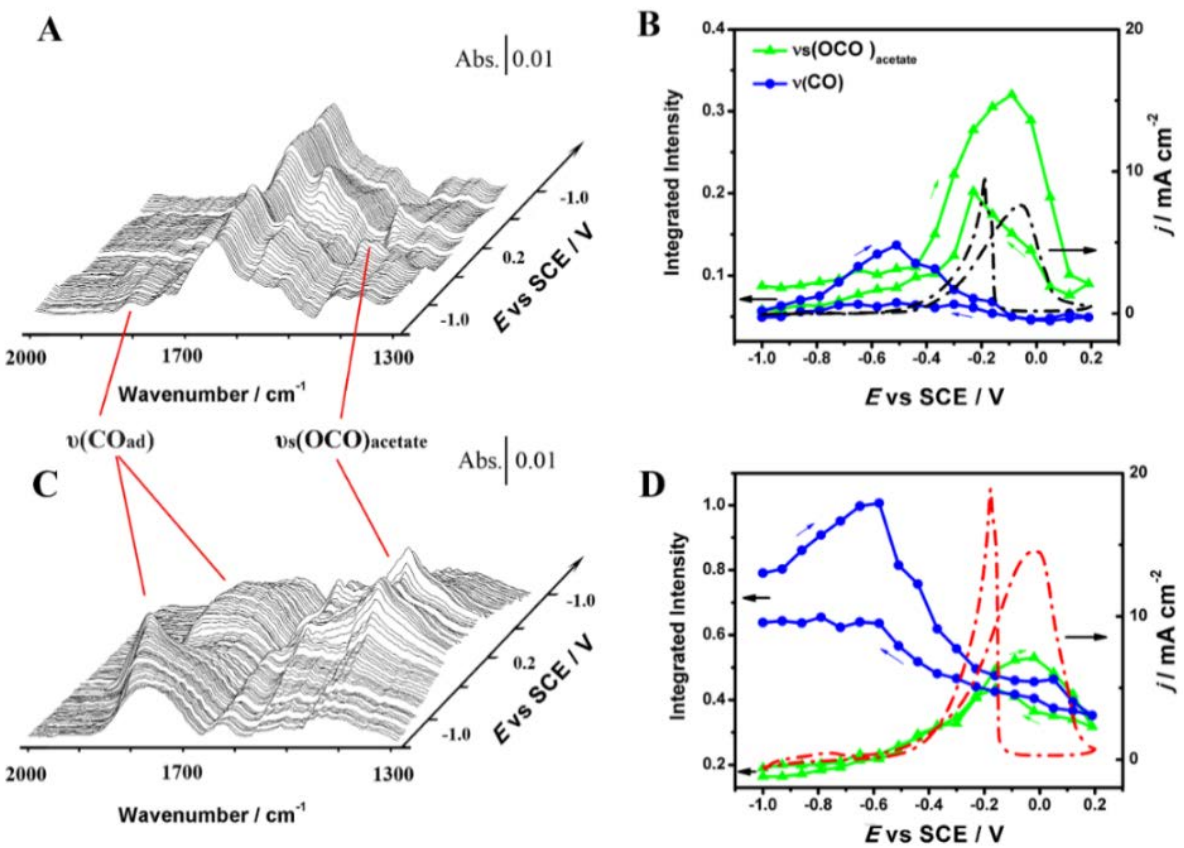

Figure 13. Potentiodynamic ATR-SEIRAS spectra on the as-deposited Pd-Ni-P film (A) and the de-alloyed film $(\mathbf{C})$ in $0.1 \mathrm{M} \mathrm{NaOH}+0.5 \mathrm{M}$ ethanol; Potential-dependent band intensities for $v\left(\mathrm{CO}_{\mathrm{ad}}\right)$ (blue) and $v_{\mathrm{s}(\mathrm{OCO})}$ of adsorbed acetate (green) with corresponding $\mathrm{CVs}$ recorded at $5 \mathrm{mV} \cdot \mathrm{s}^{-1}$ on the as-deposited $\mathrm{Pd}-\mathrm{Ni}-\mathrm{P}$ film (B) and the de-alloyed film (D) in $0.1 \mathrm{M} \mathrm{NaOH}+0.5 \mathrm{M}$ ethanol. Reproduced with permission from Reference [24]. Copyright 2014, Elsevier. 


\section{Conclusions and Outlook}

From the survey of experimental and theoretical studies, some basic principles for rational design of high performance EOR catalysts can be obtained. The catalysts should have (i) active surface sites for $\mathrm{C}-\mathrm{C}$ bond breaking; (ii) a suitable surface composition to increase selectivity for $\mathrm{CO}_{2}$ formation; (iii) the ability to facilitate the adsorption and activation of water for the removal of $\mathrm{CO}$ and $-\mathrm{CH}_{x}$ species. Utilizing these design guidelines, researchers have developed many new catalysts with higher selectivity, activity, and longer durability. These advances have significantly propelled the development of DEFCs.

Despite this progress, several fundamental and practical issues of catalysts remain to be addressed. From a fundamental point of view, the EOR mechanism is far from solidified. Some key aspects need to be clarified. These include finding the key factors in determining whether EOR goes through the C1 pathway or the $\mathrm{C} 2$ pathway; identifying intermediates during the $\mathrm{C}-\mathrm{C}$ cleavage step in the $\mathrm{C} 1$ pathway; and understanding the nature of the intermediates, especially their adsorption mode on Pt and Pd surfaces. Until these issues are satisfactorily addressed, the rational design of high performance catalysts for DEFCs will remain in its infancy. From a practical point of view, the reported methods for synthesizing high performance catalysts are not suitable for large scale commercial production. We believe efforts in these directions are essential for the further development and deployment of commercially viable DEFCs.

\section{Acknowledgements}

This work is supported by the 973 Program (No. 2015CB932303) of MOST and NSFC (Nos. 21473039 and 21273046) to W.-B.C and the US-NSF (CHE 1156425) to SZ.

\section{Author Contributions}

Wen-Bin Cai conceived the project. Ye Wang wrote the first draft of the manuscript which was then revised by Shouzhong Zou and Wen-Bin Cai. All the authors researched the literature.

\section{Conflicts of Interest}

The authors declare no conflict of interest.

\section{Reference}

1. Antolini, E.; Gonzalez, E.R. Alkaline direct alcohol fuel cells. J. Power Sources 2010, 195, 3431-3450.

2. Kamarudin, M.Z.F.; Kamarudin, S.K.; Masdar, M.S.; Daud, W.R.W. Review: Direct ethanol fuel cells. Int. J. Hydrogen Energy 2013, 38, 9438-9453.

3. Teng, X. Anodic Catalyst Design for the Ethanol Oxidation Fuel Cell. Available online: http://www.formatex.info/energymaterialsbook/book/473-484.pdf (accessed on 17 August 2015).

4. Yao, L.X.; Chang, Y.H. Shaping china's energy security: The impact of domestic reforms. Energy Policy 2015, 77, 131-139. 
5. Xuan, J.; Leung, M.K.; Leung, D.Y.; Ni, M. A review of biomass-derived fuel processors for fuel cell systems. Renew. Sustain. Energy Rev. 2009, 13, 1301-1313.

6. Wee, J.-H. Applications of proton exchange membrane fuel cell systems. Renew. Sustain. Energy Rev. 2007, 11, 1720-1738.

7. Antolini, E. Catalysts for direct ethanol fuel cells. J. Power Sources 2007, 170, 1-12.

8. Rao, L.; Jiang, Y.; Zhang, B.; You, L.; Li, Z.; Sun, S. Electrocatalytic oxidation of ethanol. Prog. Chem. 2014, 26, 727-736.

9. Li, M.; Kowal, A.; Sasaki, K.; Marinkovic, N.; Su, D.; Korach, E.; Liu, P.; Adzic, R.R. Ethanol oxidation on the ternary $\mathrm{Pt}-\mathrm{Rh}-\mathrm{SnO}_{2} / \mathrm{C}$ electrocatalysts with varied $\mathrm{Pt}: \mathrm{Rh}: \mathrm{Sn}$ ratios. Electrochim. Acta 2010, 55, 4331-4338.

10. Demirci, U.B. Theoretical means for searching bimetallic alloys as anode electrocatalysts for direct liquid-feed fuel cells. J. Power Sources 2007, 173, 11-18.

11. Bianchini, C.; Shen, P.K. Palladium-based electrocatalysts for alcohol oxidation in half cells and in direct alcohol fuel cells. Chem. Rev. 2009, 109, 4183-4206.

12. Antolini, E. Palladium in fuel cell catalysis. Energy Environ. Sci. 2009, 2, 915-931.

13. Chang, S.C.; Leung, L.W.H.; Weaver, M.J. Metal crystallinity effects in electrocatalysis as probed by real-time FTIR spectroscopy: Electrooxidation of formic acid, methanol, and ethanol on ordered low-index platinum surfaces. J. Phys. Chem. 1990, 94, 6013-6021.

14. Hitmi, H.; Belgsir, E.; Léger, J.-M.; Lamy, C.; Lezna, R. A kinetic analysis of the electro-oxidation of ethanol at a platinum electrode in acid medium. Electrochim. Acta 1994, 39, 407-415.

15. Vigier, F.; Coutanceau, C.; Hahn, F.; Belgsir, E.; Lamy, C. On the mechanism of ethanol electro-oxidation on Pt and PtSn catalysts: Electrochemical and in situ IR reflectance spectroscopy studies. J. Electroanal. Chem. 2004, 563, 81-89.

16. Raskó, J.; Dömök, M.; Baán, K.; Erdőhelyi, A. FTIR and mass spectrometric study of the interaction of ethanol and ethanol-water with oxide-supported platinum catalysts. Appl. Catal. A 2006, 299, 202-211.

17. Fang, X.; Wang, L.; Shen, P.K.; Cui, G.; Bianchini, C. An in situ fourier transform infrared spectroelectrochemical study on ethanol electrooxidation on Pd in alkaline solution. J. Power Sources 2010, 195, 1375-1378.

18. Lai, S.C.S.; Kleijn, S.E.F.; Ozturk, F.T.Z.; Vellinga, V.C.V.; Koning, J.; Rodriguez, P.; Koper, M.T.M. Effects of electrolyte $\mathrm{pH}$ and composition on the ethanol electro-oxidation reaction. Catal. Today 2010, 154, 92-104.

19. Zhou, Z.Y.; Wang, Q.A.; Lin, J.L.; Tian, N.; Sun, S.G. In situ FTIR spectroscopic studies of electrooxidation of ethanol on Pd electrode in alkaline media. Electrochim. Acta 2010, 55, 7995-7999.

20. Christensen, P.A.; Jones, S.W.M.; Hamnett, A. In situ FTIR studies of ethanol oxidation at polycrystalline Pt in alkaline solution. J. Phys. Chem. C 2012, 116, 26109-26109.

21. Christensen, P.A.; Jones, S.W.; Hamnett, A. An in situ FTIR spectroscopic study of the electrochemical oxidation of ethanol at a Pb-modified polycrystalline Pt electrode immersed in aqueous KOH. Phys. Chem. Chem. Phys. 2013, 15, 17268-17276. 
22. Anjos, D.M.; Hahn, F.; Leger, J.M.; Kokoh, K.B.; Tremiliosi, G. In situ FTIRS studies of the electrocatalytic oxidation of ethanol on Pt alloy electrodes. J. Solid State Electrochem. 2007, 11, 1567-1573.

23. Yang, Y.-Y.; Ren, J.; Li, Q.-X.; Zhou, Z.-Y.; Sun, S.-G.; Cai, W.-B. Electrocatalysis of ethanol on a Pd electrode in alkaline media: An in situ attenuated total reflection surface-enhanced infrared absorption spectroscopy study. ACS Catal. 2014, 4, 798-803.

24. Wang, Y.; Jiang, K.; Cai, W.-B. Enhanced electrocatalysis of ethanol on dealloyed Pd-Ni-P film in alkaline media: An infrared spectroelectrochemical investigation. Electrochim. Acta 2015, 162, 100-107.

25. Leung, L.W.H.; Chang, S.C.; Weaver, M.J. Real-time FTIR spectroscopy as an electrochemical mechanistic probe-Electrooxidation of ethanol and related species on well-defined $\operatorname{Pt}(111)$ surfaces. J. Electroanal. Chem. 1989, 266, 317-336.

26. Shao, M.H.; Adzic, R.R. Electrooxidation of ethanol on a Pt electrode in acid solutions: In situ ATR-SEIRAS study. Electrochim. Acta 2005, 50, 2415-2422.

27. Willsau, J.; Heitbaum, J. Elementary steps of ethanol oxidation on Pt in sulfuric acid as evidenced by isotope labelling. J. Electroanal. Chem. Interface 1985, 194, 27-35.

28. Iwasita, T.; Pastor, E. A DEMS and FTIR spectroscopic investigation of adsorbed ethanol on polycrystalline platinum. Electrochim. Acta 1994, 39, 531-537.

29. Wang, J.; Wasmus, S.; Savinell, R. Evaluation of ethanol, 1-propanol, and 2-propanol in a direct oxidation polymer-electrolyte fuel cell a real-time mass spectrometry study. J. Electrochem. Soc. 1995, 142, 4218-4224.

30. Wang, H.; Jusys, Z.; Behm, R.J. Ethanol electrooxidation on a carbon-supported Pt catalyst: Reaction kinetics and product yields. J. Phys. Chem. B 2004, 108, 19413-19424.

31. Wang, H.; Jusys, Z.; Behm, R.J. Ethanol and acetaldehyde adsorption on a carbon-supported Pt catalyst: A comparative DEMS study. Fuel Cells 2004, 4, 113-125.

32. Colmenares, L.; Wang, H.; Jusys, Z.; Jiang, L.; Yan, S.; Sun, G.Q.; Behm, R.J. Ethanol oxidation on novel, carbon supported Pt alloy catalysts-model studies under defined diffusion conditions. Electrochim. Acta 2006, 52, 221-233.

33. Wang, H.; Jusys, Z.; Behm, R. Ethanol electro-oxidation on carbon-supported Pt, PtRu and Pt 3 Sn catalysts: A quantitative DEMS study. J. Power Sources 2006, 154, 351-359.

34. Rao, V.; Cremers, C.; Stimming, U. Investigation of the ethanol electro-oxidation in alkaline membrane electrode assembly by differential electrochemical mass spectrometry. Fuel Cells 2007, 7, 417-423.

35. Wang, Q.; Sun, G.Q.; Jiang, L.H.; Xin, Q.; Sun, S.G.; Jiang, Y.X.; Chen, S.P.; Jusys, Z.; Behm, R.J. Adsorption and oxidation of ethanol on colloid-based $\mathrm{Pt} / \mathrm{C}, \mathrm{PtRu} / \mathrm{C}$ and $\mathrm{Pt} 3 \mathrm{Sn} / \mathrm{C}$ catalysts: In situ FTIR spectroscopy and on-line DEMS studies. Phys. Chem. Chem. Phys. 2007, 9, 2686-2696.

36. Figueiredo, M.C.; Aran-Ais, R.M.; Feliu, J.M.; Kontturi, K.; Kallio, T. Pt catalysts modified with Bi: Enhancement of the catalytic activity for alcohol oxidation in alkaline media. J. Catal. 2014, 312, 78-86. 
37. Sun, S.; Halseid, M.C.; Heinen, M.; Jusys, Z.; Behm, R.J. Ethanol electrooxidation on a carbon-supported Pt catalyst at elevated temperature and pressure: A high-temperature/high-pressure DEMS study. J. Power Sources 2009, 190, 2-13.

38. Kavanagh, R.; Cao, X.M.; Lin, W.F.; Hardacre, C.; Hu, P. Origin of low $\mathrm{CO}_{2}$ selectivity on platinum in the direct ethanol fuel cell. Angew. Chem. Int. Ed. Engl. 2012, 51, 1572-1575.

39. Sheng, T.; Lin, W.F.; Hardacre, C.; Hu, P. Role of water and adsorbed hydroxyls on ethanol electrochemistry on Pd: New mechanism, active centers, and energetics for direct ethanol fuel cell running in alkaline medium. J. Phys. Chem. C 2014, 118, 5762-5772.

40. Sheng, T.; Lin, W.-F.; Hardacre, C.; Hu, P. Significance of $\beta$-dehydrogenation in ethanol electro-oxidation on platinum doped with Ru, Rh, Pd, Os and Ir. Phys. Chem. Chem. Phys. 2014, 16, 13248-13254.

41. Neurock, M. First-Principles Modeling for the Electro-Oxidation of Small Molecules. In Handbook of Fuel Cells; Vielstich, W.G., Lamm, A., Yokokawa, H., Eds.; John Wiley \& Sons, Ltd.: Hoboken, NJ, USA, 2010.

42. Cui, G.F.; Song, S.Q.; Shen, P.K.; Kowal, A.; Bianchini, C. First-principles considerations on catalytic activity of Pd toward ethanol oxidation. J. Phys. Chem. C 2009, 113, 15639-15642.

43. Wang, H.F.; Liu, Z.P. Comprehensive mechanism and structure-sensitivity of ethanol oxidation on platinum: New transition-state searching method for resolving the complex reaction network. J. Am. Chem. Soc. 2008, 130, 10996-11004.

44. Wang, H.F.; Liu, Z.P. Selectivity of direct ethanol fuel cell dictated by a unique partial oxidation channel. J. Phys. Chem. C 2007, 111, 12157-12160.

45. Asiri, H.A.; Anderson, A.B. Mechanisms for ethanol electrooxidation on Pt(111) and adsorption bond strengths defining an ideal catalyst. J. Electrochem. Soc. 2015, 162, F115-F122.

46. Zhiani, M.; Majidi, S.; Rostami, H.; Taghiabadi, M.M. Comparative study of aliphatic alcohols electrooxidation on zero-valent palladium complex for direct alcohol fuel cells. Int. J. Hydrogen Energy 2015, 40, 568-576.

47. Liang, Z.X.; Zhao, T.S.; Xu, J.B.; Zhu, L.D. Mechanism study of the ethanol oxidation reaction on palladium in alkaline media. Electrochim. Acta 2009, 54, 2203-2208.

48. Buso-Rogero, C.; Herrero, E.; Feliu, J.M. Ethanol oxidation on Pt single-crystal electrodes: Surface-structure effects in alkaline medium. Chemphyschem 2014, 15, 2019-2028.

49. Zhou, W.J.; Li, M.; Zhang, L.; Chan, S.H. Supported PtAu catalysts with different nano-structures for ethanol electrooxidation. Electrochim. Acta 2014, 123, 233-239.

50. Hammer, B.; Nørskov, J.K. Theoretical Surface Science and Catalysis-Calculations and Concepts. Adv. Catal. 2000, 45, 71-129.

51. Srinivasan, S.; Dave, B.B.; Murugesamoorthi, K.A.; Parthasarathy, A.; Appleby, A.J. Overview of Fuel Cell Technology. In Fuel cell Systems; Plenum Press: New York, NY, USA, 1993.

52. Lamy, C.; Belgsir, E.; Leger, J. Electrocatalytic oxidation of aliphatic alcohols: Application to the direct alcohol fuel cell (DAFC). J. Appl. Electrochem. 2001, 31, 799-809.

53. Zhou, W.; Zhou, Z.; Song, S.; Li, W.; Sun, G.; Tsiakaras, P.; Xin, Q. Pt based anode catalysts for direct ethanol fuel cells. Appl. Catal. B 2003, 46, 273-285.

54. Lai, S.C.S.; Koper, M.T.M. Ethanol electro-oxidation on platinum in alkaline media. Phys. Chem. Chem. Phys. 2009, 11, 10446-10456. 
55. Camara, G.A.; Iwasita, T. Parallel pathways of ethanol oxidation: The effect of ethanol concentration. J. Electroanal. Chem. 2005, 578, 315-321.

56. Belgsir, E.M.; Bouhier, E.; Yei, H.E.; Kokoh, K.B.; Beden, B.; Huser, H.; Leger, J.M.; Lamy, C. Electrosynthesis in aqueous medium: A kinetic study of the electrocatalytic oxidation of oxygenated organic molecules. Electrochim. Acta 1991, 36, 1157-1164.

57. Tarnowski, D.J.; Korzeniewski, C. Effects of surface step density on the electrochemical oxidation of ethanol to acetic acid. J. Phys. Chem. B 1997, 101, 253-258.

58. Kutz, R.B.; Braunschweig, B.; Mukherjee, P.; Dlott, D.D.; Wieckowski, A. Study of ethanol electrooxidation in alkaline electrolytes with isotope labels and sum-frequency generation. J. Phys. Chem. Lett. 2011, 2, 2236-2240.

59. Ke, X.; Deng, L.L.; Shen, P.K.; Cu, G.F. Electrochemical quartz crystal microbalance (EQCM) characterization of electrodeposition and catalytic activity of Pd-based electrocatalysts for ethanol oxidation. Chem. Res. Chin. Univ. 2010, 26, 443-448.

60. Huang, L.; Sorte, E.; Sun, S.-G.; Tong, Y.Y.J. A straightforward implementation of in situ solution electrochemical ${ }^{13} \mathrm{C}$ NMR spectroscopy for studying reactions on commercial electrocatalysts: Ethanol oxidation. Chem. Commun. 2015, 51, 8086-8088.

61. Leung, L.W.H.; Weaver, M.J. Real-time FTIR spectroscopy as a quantitative kinetic probe of competing electrooxidation pathways of small organic molecules. J. Phys. Chem. 1988, 92, 4019-4022.

62. Gao, P.; Chang, S.C.; Zhou, Z.H.; Weaver, M.J. Electrooxidation pathways of simple alcohols at platinum in pure nonaqueous and concentrated aqueous environments as studied by real-time FTIR spectroscopy. J. Electroanal. Chem. 1989, 272, 161-178.

63. Buso-Rogero, C.; Grozovski, V.; Vidal-Iglesias, F.J.; Solla-Gullon, J.; Herrero, E.; Feliu, J.M. Surface structure and anion effects in the oxidation of ethanol on platinum nanoparticles. $J$. Mater. Chem. A 2013, 1, 7068-7076.

64. Paulino, M.E.; Nunes, L.M.; Gonzalez, E.R.; Tremiliosi-Filho, G. In situ FTIR spectroscopic study of ethanol oxidation on Pt (111)/Rh/Sn surface: The anion effect. Electrochem. Commun. 2015, 52, 85-88.

65. Lai, S.C.; Koper, M.T. Electro-oxidation of ethanol and acetaldehyde on platinum single-crystal electrodes. Faraday Discuss. 2009, 140, 399-416.

66. Ma, L.; Chu, D.; Chen, R. Comparison of ethanol electro-oxidation on Pt/C and Pd/C catalysts in alkaline media. Int. J. Hydrogen Energy 2012, 37, 11185-11194.

67. Zhou, Z.-Y.; Chen, D.-J.; Li, H.; Wang, Q.; Sun, S.-G. Electrooxidation of dimethoxymethane on a platinum electrode in acidic solutions studied by in situ FTIR spectroscopy. J. Phys. Chem. C 2008, 112, 19012-19017.

68. Osawa, M. Surface-Enhanced Infrared Absorption Spectroscopy. In Handbook of Vibrational Spectroscopy; Osawa, M.C., Griffiths, P.R., Eds.; Wiley: New York, NY, USA; Chichester, UK, 2002; Volume 1, pp. 785-799.

69. Yang, Y.Y.; Zhang, H.X.; Cai, W.B. Recent experimental progresses on electrochemical ATR-SEIRAS. J. Electrochem. 2013, 19, 6-16. 
70. Heinen, M.; Jusys, Z.; Behm, R.J. Ethanol, acetaldehyde and acetic acid adsorption/electrooxidation on a Pt thin film electrode under continuous electrolyte flow: An in situ ATR-FTIRs flow cell study. J. Phys. Chem. C 2010, 114, 9850-9864.

71. Bittins-Cattaneo, B.; Wilhelm, S.; Cattaneo, E.; Buschmann, H.W.; Vielstich, W. Intermediates and products of ethanol oxidation on platinum in acid solution. Ber. Bunsenges. Phys. Chem. 1988, 92, 1210-1218.

72. Lai, S.C.; Koper, M.T. The influence of surface structure on selectivity in the ethanol electro-oxidation reaction on platinum. J. Phys. Chem. Lett. 2010, 1, 1122-1125.

73. Norskov, J.K.; Bligaard, T.; Rossmeisl, J.; Christensen, C.H. Towards the computational design of solid catalysts. Nat. Chem. 2009, 1, 37-46.

74. Da Silva, S.G.; Silva, J.C.M.; Buzzo, G.S.; de Souza, R.F.B.; Spinace, E.V.; Neto, A.O.; Assumpcao, M.H.M.T. Electrochemical and fuel cell evaluation of PtAu/C electrocatalysts for ethanol electro-oxidation in alkaline media. Int. J. Hydrogen Energy 2014, 39, 10121-10127.

75. Climent, V.; Gómez, R.; Orts, J.M.; Feliu, J.M. Thermodynamic analysis of the temperature dependence of oh adsorption on $\mathrm{Pt}(111)$ and $\mathrm{Pt}(100)$ electrodes in acidic media in the absence of specific anion adsorption. J. Phys. Chem. B 2006, 110, 11344-11351.

76. Kowal, A.; Li, M.; Shao, M.; Sasaki, K.; Vukmirovic, M.; Zhang, J.; Marinkovic, N.; Liu, P.; Frenkel, A.; Adzic, R. Ternary $\mathrm{Pt} / \mathrm{Rh} / \mathrm{SnO}_{2}$ electrocatalysts for oxidizing ethanol to $\mathrm{CO}_{2}$. Nat. Mater. 2009, 8, 325-330.

77. Assumpção, M.; Nandenha, J.; Buzzo, G.; Silva, J.; Spinacé, E.; Neto, A.; de Souza, R. The effect of ethanol concentration on the direct ethanol fuel cell performance and products distribution: A study using a single fuel cell/attenuated total reflectance-fourier transform infrared spectroscopy. J. Power Sources 2014, 253, 392-396.

78. Greeley, J.; Norskov, J.K.; Mavrikakis, M. Electronic structure and catalysis on metal surfaces. Annu. Rev. Phys. Chem. 2002, 53, 319-348.

79. Rabis, A.; Rodriguez, P.; Schmidt, T.J. Electrocatalysis for polymer electrolyte fuel cells: Recent achievements and future challenges. ACS Catal. 2012, 2, 864-890.

80. Du, W.X.; Mackenzie, K.E.; Milano, D.F.; Deskins, N.A.; Su, D.; Teng, X.W. Palladium-Tin alloyed catalysts for the ethanol oxidation reaction in an alkaline medium. ACS Catal. 2012, 2, 287-297.

81. Zhu, W.; Ke, J.; Wang, S.-B.; Ren, J.; Wang, H.-H.; Zhou, Z.-Y.; Si, R.; Zhang, Y.-W.; Yan, C.-H. Shaping single-crystalline trimetallic $\mathrm{Pt}-\mathrm{Pd}-\mathrm{Rh}$ nanocrystals toward high-efficiency $\mathrm{C}-\mathrm{C}$ splitting of ethanol in conversion to $\mathrm{CO}_{2}$. ACS Catal. 2015, 5, 1995-2008.

82. Camara, G.A.; de Lima, R.B.; Iwasita, T. Catalysis of ethanol electrooxidation by PtRu: The influence of catalyst composition. Electrochem. Commun. 2004, 6, 812-815.

83. Neto, A.O.; Giz, M.J.; Perez, J.; Ticianelli, E.A.; Gonzalez, E.R. The electro-oxidation of ethanol on Pt-Ru and Pt-Mo particles supported on high-surface-area carbon. J. Electrochem. Soc. 2002, 149, A272-A279.

84. Lamy, C.; Rousseau, S.; Belgsir, E.M.; Coutanceau, C.; Leger, J.M. Recent progress in the direct ethanol fuel cell: Development of new platinum-tin electrocatalysts. Electrochim. Acta 2004, 49, 3901-3908. 
85. Zhou, W.J.; Song, S.Q.; Li, W.Z.; Zhou, Z.H.; Sun, G.Q.; Xin, Q.; Douvartzides, S.; Tsiakaras, P. Direct ethanol fuel cells based on PtSn anodes: The effect of Sn content on the fuel cell performance. J. Power Sources 2005, 140, 50-58.

86. Tayal, J.; Rawat, B.; Basu, S. Effect of addition of rhenium to Pt-based anode catalysts in electro-oxidation of ethanol in direct ethanol PEM fuel cell. Int. J. Hydrogen Energy 2012, 37, 4597-4605.

87. He, Q.G.; Shyam, B.; Macounova, K.; Krtil, P.; Ramaker, D.; Mukerjee, S. Dramatically enhanced cleavage of the $\mathrm{C}-\mathrm{C}$ bond using an electrocatalytically coupled reaction. J. Am. Chem. Soc. 2012, 134, 8655-8661.

88. Suffredini, H.B.; Salazar-Banda, G.R.; Avaca, L.A. Enhanced ethanol oxidation on $\mathrm{PbO}_{x}$-containing electrode materials for fuel cell applications. J. Power Sources 2007, 171, 355-362.

89. Huang, Y.; Cai, J.; Liu, M.; Guo, Y. Fabrication of a novel PtPbBi/C catalyst for ethanol electro-oxidation in alkaline medium. Electrochim. Acta 2012, 83, 1-6.

90. Matsumoto, F. Ethanol and methanol oxidation activity of PtPb, PtBi, and PtBi2 intermetallic compounds in alkaline media. Electrochemistry 2012, 80, 132-138.

91. Gunji, T.; Tanabe, T.; Jeevagan, A.J.; Usui, S.; Tsuda, T.; Kaneko, S.; Saravanan, G.; Abe, H.; Matsumoto, F. Facile route for the preparation of ordered intermetallic $\mathrm{Pt}_{3} \mathrm{~Pb}-\mathrm{PtPb}$ core-shell nanoparticles and its enhanced activity for alkaline methanol and ethanol oxidation. J. Power Sources 2015, 273, 990-998.

92. Tusi, M.M.; Polanco, N.S.; da Silva, S.G.; Spinacé, E.V.; Neto, A.O. The high activity of PtBi/C electrocatalysts for ethanol electro-oxidation in alkaline medium. Electrochem. Commun. 2011, 13, 143-146.

93. Figueiredo, M.C.; Santasalo-Aarnio, A.; Vidal-Iglesias, F.J.; Solla-Gullon, J.; Feliu, J.M.; Kontturi, K.; Kallio, T. Tailoring properties of platinum supported catalysts by irreversible adsorbed adatoms toward ethanol oxidation for direct ethanol fuel cells. Appl Catal. B 2013, 140, 378-385.

94. Li, M.; Cullen, D.A.; Sasaki, K.; Marinkovic, N.S.; More, K.; Adzic, R.R. Ternary electrocatalysts for oxidizing ethanol to carbon dioxide: Making Ir capable of splitting $\mathrm{C}-\mathrm{C}$ bond. J. Am. Chem. Soc. 2013, 135, 132-141.

95. Dutta, A.; Ouyang, J.Y. Ternary niaupt nanoparticles on reduced graphene oxide as catalysts toward the electrochemical oxidation reaction of ethanol. ACS Catal. 2015, 5, 1371-1380.

96. Jacob, J.M.; Corradini, P.G.; Antolini, E.; Santos, N.A.; Perez, J. Electro-oxidation of ethanol on ternary Pt-Sn-Ce/C catalysts. Appl. Catal. B 2015, 165, 176-184.

97. Zhao, Y.H.; Wang, R.Y.; Han, Z.X.; Li, C.Y.; Wang, Y.S.; Chi, B.; Li, J.Q.; Wang, X.J. Electrooxidation of methanol and ethanol in acidic medium using a platinum electrode modified with lanthanum-doped tantalum oxide film. Electrochim. Acta 2015, 151, 544-551.

98. Datta, J.; Dutta, A.; Mukherjee, S. The beneficial role of the cometals Pd and Au in the carbon-supported PtPdAu catalyst toward promoting ethanol oxidation kinetics in alkaline fuel cells: Temperature effect and reaction mechanism. J. Phys. Chem. C 2011, 115, 15324-15334.

99. Yang, X.; Yang, Q.; Xu, J.; Lee, C.-S. Bimetallic PtPd nanoparticles on nafion-graphene film as catalyst for ethanol electro-oxidation. J. Mater. Chem. 2012, 22, 8057-8062. 
100. Liao, F.L.; Lo, T.W.B.; Sexton, D.; Qu, J.; Wu, C.T.; Tsang, S.C.E. PdFe nanoparticles as selective catalysts for $\mathrm{C}-\mathrm{C}$ cleavage in hydrogenolysis of vicinal diol units in biomass-derived chemicals. Catal. Sci. Technol. 2015, 5, 887-896.

101. Almeida, T.S.; van Wassen, A.R.; van Dover, R.B.; de Andrade, A.R.; Abruña, H.D. Combinatorial PtSnM ( $\mathrm{M}=\mathrm{Fe}, \mathrm{Ni}, \mathrm{Ru}$ and $\mathrm{Pd})$ nanoparticle catalyst library toward ethanol electrooxidation. J. Power Sources 2015, 284, 623-630.

102. Carmo, M.; Sekol, R.C.; Ding, S.Y.; Kumar, G.; Schroers, J.; Taylor, A.D. Bulk metallic glass nanowire architecture for electrochemical applications. ACS Nano 2011, 5, 2979-2983.

103. Li, L.; Yuan, X.X.; Xia, X.Y.; Du, J.; Ma, Z.; Ma, Z.F. Effects of Mo doping on properties of $\mathrm{Pt} / \mathrm{C}$ as catalyst towards electro-oxidation of ethanol. J. Inorg. Mater. 2014, 29, 1044-1048.

104. Jiang, L.; Colmenares, L.; Jusys, Z.; Sun, G.Q.; Behm, R.J. Ethanol electrooxidation on novel carbon supported $\mathrm{Pt} / \mathrm{SnO}_{x} / \mathrm{C}$ catalysts with varied $\mathrm{Pt}: \mathrm{Sn}$ ratio. Electrochim. Acta 2007, 53, 377-389.

105. Li, M.; Liu, P.; Adzic, R.R. Platinum monolayer electrocatalysts for anodic oxidation of alcohols. J. Phys. Chem. Lett. 2012, 3, 3480-3485.

106. Cheng, F.L.; Dai, X.C.; Wang, H.; Jiang, S.P.; Zhang, M.; Xu, C.W. Synergistic effect of Pd-Au bimetallic surfaces in Au-covered Pd nanowires studied for ethanol oxidation. Electrochim. Acta 2010, 55, 2295-2298.

107. Mourdikoudis, S.; Chirea, M.; Zanaga, D.; Altantzis, T.; Mitrakas, M.; Bals, S.; Liz-Marzán, L.M.; Perez-Juste, J.; Pastoriza-Santos, I. Governing the morphology of Pt-Au heteronanocrystals with improved electrocatalytic performance. Nanoscale 2015, 7, 8739-8747.

108. Figueiredo, M.C.; Solla-Gullón, J.; Vidal-Iglesias, F.J.; Nisula, M.; Feliu, J.M.; Kallio, T. Carbon-supported shape-controlled Pt nanoparticle electrocatalysts for direct alcohol fuel cells. Electrochem. Commun. 2015, 55, 47-50.

109. Tian, N.; Zhou, Z.-Y.; Sun, S.-G.; Ding, Y.; Wang, Z.L. Synthesis of tetrahexahedral platinum nanocrystals with high-index facets and high electro-oxidation activity. Science 2007, 316, 732-735.

110. Sheikh, A.; Silva, E.; Moares, L.; Antonini, L.; Abellah, M.Y.; Malfatti, C. Pd-based catalysts for ethanol oxidation in alkaline electrolyte. Am. J. Min. Metal. 2014, 2, 64-69.

111. Kumar, K.S.; Haridoss, P.; Seshadri, S.K. Synthesis and characterization of electrodeposited Ni-Pd alloy electrodes for methanol oxidation. Surf. Coat. Technol. 2008, 202, 1764-1770.

112. Hosseini-Sarvari, M.; Khanivar, A.; Moeini, F. Magnetically recoverable nano $\mathrm{Pd} / \mathrm{Fe}_{3} \mathrm{O}_{4} / \mathrm{ZnO}$ catalyst: Preparation, characterization, and application for the synthesis of 2-oxazolines and benzoxazoles. J. Mater. Sci. 2015, 50, 3065-3074.

113. Li, G.; Jiang, L.; Jiang, Q.; Wang, S.; Sun, G. Preparation and characterization of $\mathrm{Pd}_{x} \mathrm{Ag}_{y} / \mathrm{C}$ electrocatalysts for ethanol electrooxidation reaction in alkaline media. Electrochim. Acta 2011, 56, 7703-7711.

114. Zhu, L.D.; Zhao, T.S.; Xu, J.B.; Liang, Z.X. Preparation and characterization of carbon-supported sub-monolayer palladium decorated gold nanoparticles for the electro-oxidation of ethanol in alkaline media. J. Power Sources 2009, 187, 80-84.

115. Wang, H.; Xu, C.W.; Cheng, F.L.; Jiang, S.P. Pd nanowire arrays as electrocatalysts for ethanol electrooxidation. Electrochem. Commun. 2007, 9, 1212-1216. 
116. Dutta, A.; Datta, J. Outstanding catalyst performance of pdauni nanoparticles for the anodic reaction in an alkaline direct ethanol (with anion-exchange membrane) fuel cell. J. Phys. Chem. C 2012, 116, 25677-25688.

117. Wang, Y.; Shi, F.F.; Yang, Y.Y.; Cai, W.B. Carbon supported Pd-Ni-P nanoalloy as an efficient catalyst for ethanol electro-oxidation in alkaline media. J. Power Sources 2013, 243, 369-373.

118. Bahemmat, S.; Ghassemzadeh, M.; Afsharpour, M.; Harms, K. Synthesis, characterization and crystal structure of a Pd(ii) complex containing a new bis-1,2,4-triazole ligand: A new precursor for the preparation of Pd(0) nanoparticles. Polyhedron 2015, 89, 196-202.

119. Da Silva, S.G.; Assumpcao, M.H.M.T.; Silva, J.C.M.; de Souza, R.F.B.; Spinace, E.V.; Neto, A.O.; Buzzo, G.S. PdSn/C electrocatalysts with different atomic ratios for ethanol electro-oxidation in alkaline media. Int. J. Electrochem. Sci. 2014, 9, 5416-5424.

120. Mao, H.M.; Wang, L.L.; Zhu, P.P.; Xu, Q.J.; Li, Q.X. Carbon-supported PdSn $\mathrm{SnO}_{2}$ catalyst for ethanol electro-oxidation in alkaline media. Int. J. Hydrogen Energy 2014, 39, 17583-17588.

121. Bambagioni, V.; Bianchini, C.; Filippi, J.; Oberhauser, W.; Marchionni, A.; Vizza, F.; Psaro, R.; Sordelli, L.; Foresti, M.L.; Innocenti, M. Ethanol oxidation on electrocatalysts obtained by spontaneous deposition of palladium onto nickel-zinc materials. ChemSusChem 2009, 2, 99-112.

122. Takeguchi, T.; Anzai, Y.; Kikuchi, R.; Eguchi, K.; Ueda, W. Preparation and characterization of CO-tolerant Pt and Pd anodes modified with $\mathrm{SnO}_{2}$ nanoparticles for PEFC. J. Electrochem. Soc. 2007, 154, B1132-B1137.

123. Mao, H.; Huang, T.; Yu, A.-S. Facile synthesis of trimetallic $\mathrm{Cu}_{1} \mathrm{Au}_{0.15} \mathrm{Pd}_{1.5} / \mathrm{C}$ catalyst for ethanol oxidation with superior activity and stability. J. Mater. Chem. A 2014, 2, 16378-16380.

124. Shen, P.K.; Xu, C. Alcohol oxidation on nanocrystalline oxide Pd/C promoted electrocatalysts. Electrochem. Commun. 2006, 8, 184-188.

125. Wang, L.; Lavacchi, A.; Bevilacqua, M.; Bellini, M.; Fornasiero, P.; Filippi, J.; Innocenti, M.; Marchionni, A.; Miller, H.A.; Vizza, F. Energy efficiency of alkaline direct ethanol fuel cells employing nanostructured palladium electrocatalysts. Chemcatchem 2015, 7, 2214-2221.

126. Wang, Y.; Wang, X.M.; Wang, Y.Z.; Li, J.P. Acid-treatment-assisted synthesis of Pt-Sn/graphene catalysts and their enhanced ethanol electro-catalytic activity. Int. J. Hydrogen Energy 2015, 40, 990-997.

127. Xu, C.; Cheng, L.; Shen, P.; Liu, Y. Methanol and ethanol electrooxidation on Pt and Pd supported on carbon microspheres in alkaline media. Electrochem. Commun. 2007, 9, 997-1001.

128. Wang, A.L.; He, X.J.; Lu, X.F.; Xu, H.; Tong, Y.X.; Li, G.R. Palladium-Cobalt nanotube arrays supported on carbon fiber cloth as high-performance flexible electrocatalysts for ethanol oxidation. Angew. Chem. Int. Ed. 2015, 54, 3669-3673.

129. Zhao, M.; Abe, K.; Yamaura, S.-I.; Yamamoto, Y.; Asao, N. Fabrication of Pd-Ni-P metallic glass nanoparticles and their application as highly durable catalysts in methanol electro-oxidation. Chem. Mater. 2014, 26, 1056-1061.

130. Jiang, R.Z.; Tran, D.T.; McClure, J.P.; Chu, D. A class of (Pd-Ni-P) electrocatalysts for the ethanol oxidation reaction in alkaline media. ACS Catal. 2014, 4, 2577-2586.

131. Shao, A.F.; Wang, Z.B.; Chu, Y.Y.; Jiang, Z.Z.; Yin, G.P.; Liu, Y. Evaluation of the performance of carbon supported Pt-Ru-Ni-P as anode catalyst for methanol electrooxidation. Fuel Cells 2010, 10, 472-477. 
132. Lo, Y.L.; Hwang, B.J. Kinetics of ethanol oxidation on electroless $\mathrm{Ni}-\mathrm{P} / \mathrm{SnO}_{2} / \mathrm{Ti}$ electrodes in KOH solutions. J. Electrochem. Soc. 1995, 142, 445-450.

(C) 2015 by the authors; licensee MDPI, Basel, Switzerland. This article is an open access article distributed under the terms and conditions of the Creative Commons Attribution license (http://creativecommons.org/licenses/by/4.0/). 